\title{
PostScript
}

\section{Wegener's granulomatosis}

Wegener's granulomatosis (WG) is a systemic granulomatous inflammatory disease of unknown origin. It occurs at any age, with the peak incidence in the third and fourth decades. The classic diagnostic triad of WG is necrotising granuloma of the upper or lower respiratory tract, vasculitis, and nephritis Identifying a raised ANCA titre is virtually diagnostic of the disease, especially with the classic granular cytoplasmic staining pattern of neutrophils (C-ANCA). ${ }^{1}$ This disease is usually fatal if untreated; however, early diagnosis and instigation of immunosuppressants such as cyclophosphamide can induce long term remission.

\section{Case report}

A 79 year old woman presented with a 2 week history of a painful, red left eye. She had mild arthritis and was also noted to be profoundly deaf, requiring hand written notes for communication. There was no history of sinus problems.

Her best corrected visual acuities were 6/18 in the right eye and 6/12 in the left eye. The left peripheral supratemporal cornea showed three areas of $80 \%$ corneal thinning, $1 \times 1 \mathrm{~mm}$ in size, with an overlying epithelial defect (Fig 1). There was adjacent conjunctival injection and moderate anterior chamber cellular activity. The other eye was normal with no signs of inflammation. Examination of her hands showed no obvious rheumatoid abnormalities. Initial investigations performed were ful blood count, electrolytes, $\mathrm{C}$ reactive protein erythrocyte sedimentation rate (ESR), and rheumatoid factor. Corneal scraping and cultures were also undertaken to exclude an infective cause. The only significant test result was a raised ESR of 94, with other tests including creatinine being within the normal range. A provisional diagnosis was made of rheumatoid corneal melt and treatment was commenced with topical dexamethasone $0.1 \%$ non-preserved hourly and oral prednisolone at $40 \mathrm{mg} / \mathrm{day}$.

After 5 days of steroid treatment, the corneal thinning was resolving and the conjunctival injection settling (Fig 2). Also by the fifth day, the patient's hearing had dramatically improved. She could now conduct a conversation at normal volume. On further questioning, she said her hearing had deteriorated only over the past few months and had ascribed it to "natural" old age deterioration. This suggested a link between her

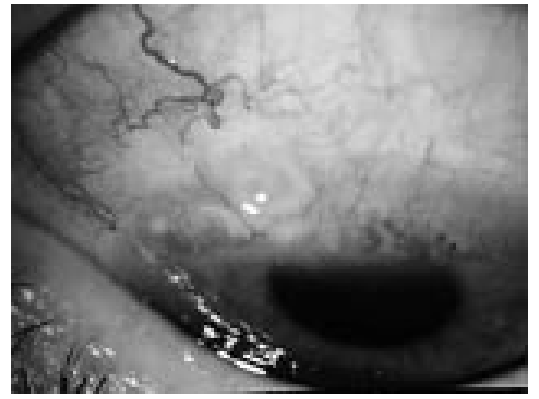

Figure 1 Peripheral corneal melt with adjacent conjunctival injection.

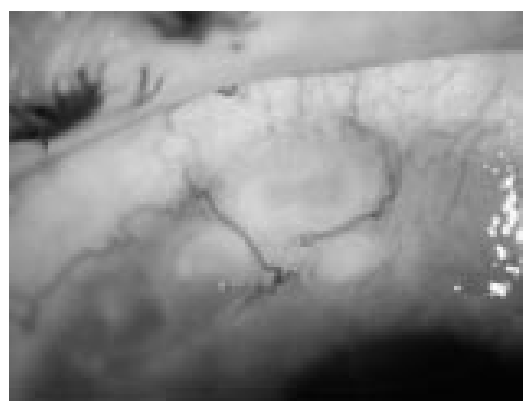

Figure 2 Resolving peripheral corneal melt and conjunctival injection.

corneal changes and hearing loss and she was investigated for Wegener's granulomatosis (WG). Her serum antineutrophil cytoplasmic antibodies (CANCA) titre was found to be raised $(>160)$. Rheumatoid factor was negative.

Oral cyclophosphamide was commenced on diagnosis of WG and the oral prednisolone slowly tapered. Her ocular inflammation, hearing, and arthritis continued to improve on treatment and at the 2 month follow up, there was minimal peripheral corneal thinning and no inflammation. Best corrected visual acuity in the left eye remained at 6/12. Examination by an otolaryngologist found mild hearing impairment and no significan sinus pathology. Rheumatological review found only mild arthropathy.

\section{Comment}

The majority of the ocular involvement in WG is caused by focal vasculitis, involving the anterior and/or posterior segment of the eye and corneal melting has been reported in $11-16 \%$ of patients with WG. ${ }^{3}$ Profound sensorineural deafness is a less common feature, occurring in about $6 \%$ of patients on presentation. ${ }^{25}$ It occurs either secondary to inflammation of the cochlear vessels or serous otitis media. ${ }^{4}$ Other important systemic features include pyrexia, weight loss, recurrent epistaxis, sinus discharge, haemoptysis, peripheral neuropathy, cerebral vasculitis, and renal failure (major cause of death). Fortunately in this case, the patient had the limited form of WG, with no renal involvement.

This patient presented with an uncommon combination of corneal melt and profound deafness. As deafness is a relatively common problem among the elderly patient population ${ }^{6}$ it may be overlooked as an important symptom, especially if ocular pathology is the main feature at presentation. It was not until the patient's hearing improved on treatment with oral prednisolone that its significance became apparent. WG is a rare condition and early recognition and treatment are essential as the disease carries a significant risk of serious complications. A full systemic history in patients with corneal melt is important in formulating the correct diagnosis and thereby expediting the appropriate treatment.

K S Lim, GA Lee, C E Pavesio, L A Ficker Moorfields Eye Hospital, London, UK
Correspondence to: Graham A Lee, Queensland, Australia; mdglee@hotmail.com

Accepted for publication 12 August 2002

\section{References}

1 Van der Woude FJ. Anticytoplasmic antibodies in Wegener's granulomatosis. Lancet 1985;2:48.

2 Fauci AS, Haynes BF, Katz P, et al. Wegener's granulomatosis: prospective clinical and therapeutic experience with 85 patients for 21 years. Ann Intern Med 1983;98:76-85.

3 Haynes BF, Fishman ML, Fauci AS, et al. The ocular manifestations of Wegener's granulomatosis. Fifteen years' experience and review of the literature. Am J Med 1977;63:131-41.

4 Bullen CL, Liesegang TJ, MacDonald TJ, et al Ocular complications of Wegener's granulomatosis. Ophthalmology 1983:90:279-90.

5 Thornton MA, O'Sullivan TJ. Otological Wegener's granulomatosis: a diagnostic dilemma. Clin Otolaryngol 2000;25:433-4.

6 Davis AC. The prevalence of hearing impairment and reported hearing disability among adults in Great Britain. Int J Epidemiol 1989;18:911-17.

\section{Pigmentary retinopathy, macular oedema, and abnormal ERG with mitotane treatment}

Adrenocortical carcinoma is a rare tumour with a poor prognosis. Mitotane (o, $\mathrm{p}^{\prime}$-DDD), a chemotherapy drug that suppresses the adrenal cortex and modifies peripheral steroid metabolism has been reported to cause ocular side effects including visual blurring, diplopia, cataract, toxic retinopathy with retinal haemorrhage, oedema, and papilloedema. We present a 32 year old woman with reduced visual acuity, retinal pigmentation, macular oedema, and abnormal ERG after taking mitotane. While primary hypoadrenalism in Addison's disease has never been reported to cause any retinal problem, secondary hypoadrenalism in adrenoleucodystrophy is associated with pigmentary retinopathy and other ocular findings. We postulate that the retinal problems secondary to mitotane treatment may act via a similar mechanism.

\section{Case report}

A 30 year old woman had a left nephrectomy, adrenalectomy, and chemotherapy in September 1997 following diagnosis of an adrenal carcinoma. In 1999, she was found to have secondary tumours in her lungs and liver. She was commenced on intra-arterial cisplatin and oral mitotane of up to $4.5 \mathrm{~g}$ daily for $6-8$ months, ceasing in December 1999 because of weight loss, malaise and, soon after that, marked decrease of visual acuity in both eyes. The patient had no family history of any retinal disease. She had worn glasses for myopia for 9 years with best corrected visual acuity of $6 / 4$ each eye previously.

On 2 March 2000 her visual acuity was 6/12 in the right eye and 6/60 in the left eye. She also had facial pigmentation. Funduscopy showed extensive pigmentary clumping in each eye and macular oedema in the left side (Fig 1). She was commenced on cortisone acetate and fludrocortisone to attempt to improve her vision. 


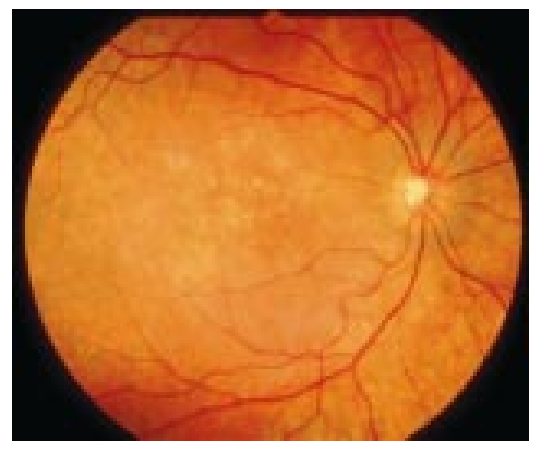

Figure 1 Right fundus showing mottled pigmentation at the macula.

One week later her visual acuity was $6 / 18$ in the right and 6/24 in the left. Fundus examination showed mottled pigmentation at the macula and mid-periphery of both eyes but macular oedema in her left eye had resolved. Disc and vessels were normal. Full field electroretinography (ERG) was performed. Her rod response (scotopic, dim blue stimulus) b-wave was $50 \%$ of normal, the cone response (photopic, red stimulus) had b-wave $75 \%$ of normal amplitude and delayed implicit time (Fig 2). The amplitude of $30 \mathrm{~Hz}$ flicker responses was also reduced. There was no significant asymmetry between the two eyes. On 30 March 2000, her visual acuity improved to $6 / 12$ in the right and 6/9 in the left. Her facial pigmentation had also faded.

\section{Comment}

Surgical resection is the treatment of choice for adrenocortical carcinoma. ${ }^{1}$ Mitotane (o, $\mathrm{p}^{\prime}$ DDD) is the only drug that causes regression of metastases and improves survival. ${ }^{23}$ Its biochemical action is unknown but data suggest that it modifies peripheral steroid metabolism and directly suppresses the adrenal cortex. The incidence of ocular side effects was $4 \%$ in a study of 132 patients. ${ }^{3}$ These effects include visual blurring, diplopia, lens opacities, optic neuritis, and a toxic retinopathy with features of papilloedema and retinal haemorrhage. In another study involving 19 patients, three patients had toxic retinopathy that included papilloedema, small retinal haemorrhages, and oedema and an other patient had a subcapsular cataract. ${ }^{4}$ To our knowledge neither pigmentary retinopathy nor abnormal ERG findings have been reported previously. Previous studies also did not mention side effects reversibility except for a case of lenticular opacities that disappeared 5 days after discontinuance of mitotane. ${ }^{3}$ In our case, the patient's visual acuity did improve significantly, with drying out of macular oedema after cessation of therapy and initiation of steroid replacement.

It is possible, however, that the ocular changes in this patient were not caused by mitotane but were secondary to cancer associated retinopathy (CAR). Its characteristic findings include attenuated retinal arterioles, with limited, if any, clinically apparent retinal pigmentary changes and cells in the vitreous humour. ${ }^{5}$ CAR was considered to be unlikely in this case because of the normal calibre of the retinal arterioles, the absence of vitreous cells, and the timing of the onset. Patients with CAR experience visual symptoms that often precede or are concurrent with the tumour diagnosis. ${ }^{6}$

Although primary hypoadrenalism in Addison's disease has never been reported to cause retinal problems, secondary hypoadrenalism in adrenoleucodystrophy is associated with pigmentary retinopathy and other ocular findings. Adrenoleucodystrophy is a group of rare lipid storage disorders with increased serum level of long chain fatty acids (C24C30). Ocular findings in adrenoleucodystrophy include visual loss secondary to visual tract demyelination and primary retinal ganglion cell degeneration, squint, cataracts, loss of corneal sensation, abnormal visual evoked potentials, and macular pigmentary changes. The retinal pigmentary changes observed histologically were different from those in retinitis pigmentosa. ${ }^{8}$

We postulate that the retinal side effects of mitotane could occur via a similar mechanism that affects the metabolism of long chain fatty acids. Mitotane causes a reduction in plasma 17-hydroxy corticosteroids level but an increase in the levels of 6-beta-hydroxyl cortisol cholesterol, liver enzymes, corticosteroid binding globulin, and sex hormone binding globulin. ${ }^{1}$ At the time of writing, there was no published information on whether mitotane treatment affects serum long chain fatty acid levels. The availability of such data will be valuable for evaluating this postulation.

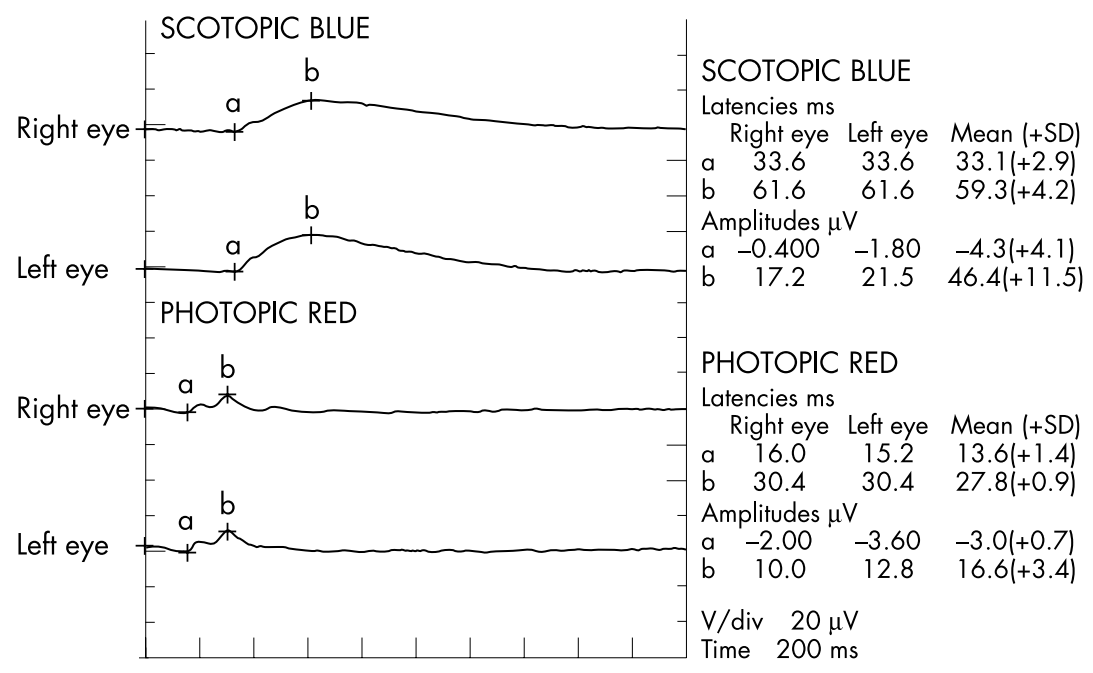

Figure 2 Full field ERG.
W T Ng, M G Toohey, L Mulhall, D A Mackey

St Vincent's Hospital, Fitzroy, Victoria, The Ballarat Eye Clinic, Ballarat, Victoria, Ocular Diagnostic Clinic and CERA, Royal Victorian Eye and Ear Hospital, East Melbourne, Victoria, Australia

Correspondence to: David Mackey; d.mackey@utas.edu.au

Accepted for publication 12 August 2002

\section{References}

1 Luton J-P, Cerdas S, Billaud L, et al. Clinical features of adrenocortical carcinoma, prognostic factors and the effect of mitotane therapy. N Engl J Med 1990;322:1 195-201.

2 Lubitz JA, Freeman L, Okun R. Mitotane use in inoperable adrenal cortical carcinoma. JAMA 1973;223:1109-12.

3 Hutter AM, Kayhoe DE. Adrenal cortical carcinoma, results of treatment with $0, p^{\prime}-D D D$ in 138 patients. Am J Med 1966;41:581-92.

4 Hoffman DL, Mattox VR. Treatment of adrenocortical carcinoma with o, $p^{\prime}-\mathrm{DDD}$. Med Clin North Am 1972:56:999-1012.

5 Jacobson DM, Thirkill CE, Tipping SJ. A clinical triad to diagnose paraneoplastic retinopathy. Ann Neurol 1990;28:162-67

6 Fishman GA, Birch DG, Holder GE, et al. Electrophysiologic testing in disorders of the retina, optic nerve and visual pathway. 2nd ed. San Francisco: The Foundation of the American Academy of Ophthalmology, 2001:118-120.

7 Traboulsi EI, Maumenee IH. Ophthalmologic manifestations of X-linked childhood adrenoleukodystrophy. Ophthalmology 1987;94:47-52.

8 Glasgow BJ, Brown $\mathrm{HH}$, Hannah JB, et al. Ocular pathologic findings in neonatal adrenoleukodystrophy. Ophthalmology 1987;94:1054-60.

\section{Coxsackievirus B4 associated uveoretinitis in an adult}

Coxsackievirus is a kind of enterovirus, which may cause respiratory and gastrointestinal symptoms, erythema, meningoencephalitis, myocarditis, pericarditis, and myositis. Although Coxsackievirus B4 is apparently a rare cause of chorioretinitis, Coxsackievirus infection and concurrent posterior segment inflammation have been disclosed in a few cases. However, iridocyclitis, scattered haemorrhagic dots, and occlusive retinal vasculitis have not previously reported as being features of Coxsackievirus B4 infectious ocular disease.

\section{Case report}

A 34 year old man was referred to our hospital with a 2 week history of inferior visual field defect and visual loss in his right eye. His left eye was asymptomatic. A few days before the onset of visual manifestations, the patient noted a prodrome of viral infection, consisting of severe headache and high grade fever of $38.0-39.2^{\circ} \mathrm{C}$, joint pain, and general malaise. There was no significant medical or family history. At the initial ophthalmic examination, his best corrected visual acuities were $10 / 20$ in the right eye and 25/20 in the left eye, and intraocular pressure was normal in both eyes. Slit lamp examination showed moderate cellular infiltration in the anterior chamber in both eyes. Humphrey central visual field testing demonstrated relative scotoma inferior to fixation in the right eye. Goldmann peripheral visual field testing was within normal limits in both eyes. Ophthalmoscopic examination disclosed subretinal exudates with haemorrhage in the parafovea and the mid-periphery of bilateral eyes (Fig 1). Moreover, scattered 

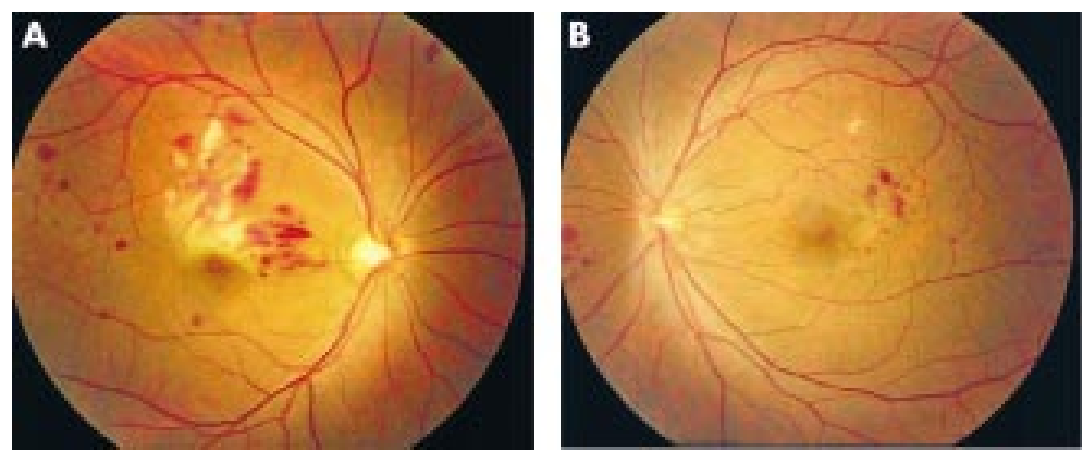

Figure 1 Photographs of right eye (A) and left eye (B) at the initial ophthalmic examination. Subretinal exudates with haemorrhage around the macula and near the disc, and scattered haemorrhagic blots are evident.

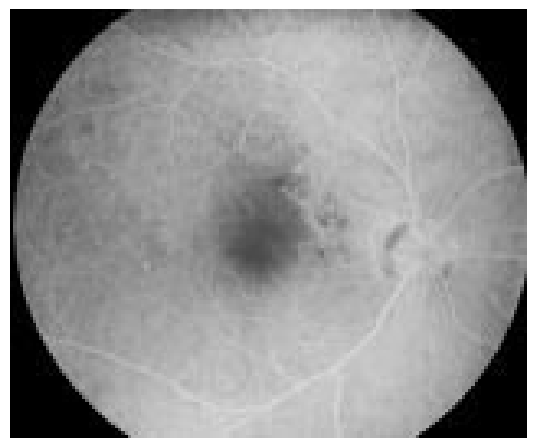

Figure 2 Fluorescein angiograms of the right eye. Note blocked fluorescence and slight dye leakage from the retinal vessels around the macula, and irregular choroidal background fluorescence.

haemorrhagic dots and blots were observed along retinal vessels. The optic discs appeared normal. Fluorescein angiography demonstrated occlusive retinal vasculitis characterised by blocked fluorescence and mild dye leakage from the retinal vessels corresponding to the lesions detected clinically, and irregular choroidal background fluorescence (Fig 2). Laboratory examination findings were normal except a white blood cell count of $10500 \times 10^{6} / 1$, GOT of $76 \mathrm{IU} / \mathrm{l}$, GPT of $209 \mathrm{IU} / \mathrm{l}$, gamma-GTP of $88 \mathrm{IU} /$, and LDH of 771 IU/A. Serological tests, however, revealed a slight elevation of serum antibody to Coxsackievirus B4, at a titre of 1:8 (neutralisation test).

The patient's general condition improved gradually without specific medication. Cellular infiltration in the anterior chamber gradually disappeared. The retinal exudative lesions reduced in size, and haemorrhage tended to decrease. Eight months after the initial ophthalmic examination, bilateral exudative lesions had improved and were replaced by scars, and most of the retinal haemorrhagic lesions had disappeared. Visual acuity was restored to 25/20 in the right eye and 30/20 in the left eye. However, relative paracentral scotoma persisted in his right eye. Antibody titre to Coxsakievirus B4 had increased, demonstrating a 16 -fold rise between the acute $(1: 8)$ and convalescent sera (1:128). Retrospectively, we diagnosed the ocular lesions in this patient as uveoretinitis induced by Coxsackievirus B4 infection.

\section{Comment}

Viruses are one of the most common causes of infections involving the posterior segment of the eye. Such infections may be congenital or acquired, and may affect primarily the retina or the choroid. Retinitis and choroiditis caused by viruses such as measles, influenza, Epstein-Barr virus, and Rift Valley fever virus typically occur on an acquired basis, subsequent to an acute viral systemic illness. Coxsakievirus associated chorioretinitis is thought to elicit the same clinical course as in other viral chorioretinitis. Coxsackievirus infection and concurrent posterior segment inflammation have been reported in a few cases, in which clinical signs and antibody titres suggested that Coxsackievirus was the responsible agent. ${ }^{1-4}$ Among them, two cases of chorioretinits associated with Coxsackievirus B4 infection were reported..$^{13}$ One was a paediatric case, and the ophthalmoscopic manifestation was described as scattered white lesions in mid-periphery of the retina. The other was an adult case, with chorioretinitis similar to the multiple evanescent white dot syndrome. ${ }^{3}$ However, the clinical features observed in our patient consisted of iridocyclitis, scattered haemorrhagic dots, and occlusive retinal vasculitis were apparently different from the two earlier reports.

Coxsackievirus infection is apparently a rare cause of uveoretinitis but, nevertheless, should be considered in the appropriate clinical setting, since it is possible that overt clinical manifestations and complications may occur depending on the severity and the location of the uveoretinal lesions.

M Takeuchi, J Sakai, M Usui

Tokyo Medical University, 6-7-1 Nishishinjuku Shinjuku-Ku, Tokyo, Japan

Correspondence to: Masaru Takeuchi takeuchi@tokyo-med.ac.jp

Accepted for publication 30 August 2002

\section{References}

1 Hirakata K, Oshima T, Azuma N Chorioretinitis induced by coxsackievirus B4 infection. Am J Ophthalmol 1990; 109:225-7.

2 Forster W, Bialasiewicz AA, Busse $H$. Coxsackievirus B3-associated panuveitis. $\mathrm{Br}$ Ophthalmol 1993;77: 182-3.

3 Kadrmas EF, Buzney SM. Coxsackievirus B4 as a cause of adult chorioretinitis. Am J Ophthalmol 1999;127:347-9.

4 Haamann P, Kessel L, Larsen M. Monofocal outer retinitis associated with hand, foot, and mouth disease caused by coxsackievirus. Am J Ophthalmol 2000;129:552-3.

\section{Evaluation of telemedicine for slit lamp examination of the eye following cataract surgery}

Ophthalmic surgery is well suited to the use of telemedicine in diagnosis and management, ${ }^{12}$ but diagnostic accuracy and reliability are critical if it is to be widely introduced. ${ }^{3}$ Moorfields Eye Hospital is located in central London and runs community outreach clinics. One clinic and operating list in Ealing is 17 miles from the central hospital. The surgical teams operate in Ealing and then return to the central hospital. We therefore investigated the use of a telemedicine link for review of postoperative cataract surgical patients aiming to assess what can be seen clearly and reliably using telemedicine and to identify what the observer using this link may potentially miss.

\section{Case report}

This study had Moorfields Eye Hospital research and ethics committee approval. Patients consecutively admitted for cataract surgery were recruited to the study and full informed written consent was obtained. A telelink of a pair of Global Telemed mobile workstations connected by three ISDN lines, with a video transmission rate of $384 \mathrm{bit} / \mathrm{s}$ was used for examinations, ${ }^{1}$ with high resolution examination being achieved by static images. Two surgeons conducted examinations, one using the slit lamp and the other using the telemedicine link. Slit lamp signs graded by the two observers comprised the presence and degree of the following - central corneal oedema, corneal oedema at the limbal section, Siedel's sign, folds in Descemet's membrane, anterior chamber depth, flare and cells, intraocular lens decentration, and lens stability. Both observers in person independently examined a group of postoperative cataract patients in order to determine agreement between practitioners.

Twelve consecutive postoperative cataract patients were recruited to the study with 10 others as a control group to assess interobserver agreement by in-person examination. The results of the study are given in Table 1.

\section{Comment}

Although interobserver variation means that telelink reliability cannot be precisely calculated in terms of sensitivity and specificity, these findings give an indication of the accuracy of slit lamp examination after cataract surgery using $384 \mathrm{~K}$ bandwidth. Examination by video telelink was relatively reliable in detecting oedema at the central cornea but did not consistently detect oedema at the corneal section, or anterior chamber flare and failed entirely to detect DM folds or anterior chamber cells. Patients enjoyed the telemedicine experience finding it reassuring to see as well as interact with their surgeon via the telelink.

Video compression algorithms used in streaming video are "lossy" and higher bandwidth increases video quality. The process begins with a good video source with low noise, since noise does not compress well. A poor quality video image is very difficult to stream successfully because of this difficulty in compression. The videoconferencing standard H-261 was implemented to provide for video compression to a given ISDN bandwidth. With increasing bandwidth there is correspondingly better quality video. A televideo link for corneal assessment in Canada using six ISDN lines (768 K) was found to be acceptable, whereas three lines ( $384 \mathrm{~K}$ ) were unacceptable (personal communication, Dr M Pop, Montreal, Canada).

The video display also affects the information observed. Broadcast video monitors are accurately colour calibrated, whereas digital compressed video to $384 \mathrm{~K}$ bandwidth has 
Table 1 Consistency of scoring by the two observers

\begin{tabular}{lll}
\hline & $\begin{array}{l}\text { Control group } \\
(\mathbf{n}=10)\end{array}$ & $\begin{array}{l}\text { Study group } \\
(\mathbf{n}=12)\end{array}$ \\
\hline Oedema of the incision $\chi^{2}=2.933, \mathrm{p}=0.087$ & $7 / 10(70 \%)$ & $4 / 12(33 \%)$ \\
Oedema of the central cornea & $7 / 10(70 \%)$ & $10 / 12(83 \%)$ \\
Descemet's folds & $10 / 10(100 \%)$ & $7 / 12(58 \%)$ \\
Anterior chamber cells & $9 / 10(90 \%)$ & $0 / 12(0 \%)$ \\
Anterior chamber flare & $9 / 10(90 \%)$ & $6 / 12(50 \%)$ \\
Lens implant stability & $9 / 10(90 \%)$ & $12 / 12(100 \%)$ \\
Management decisions & $9 / 10(90 \%)$ & $11 / 12(93 \%)$ \\
\hline
\end{tabular}

reduced colour depth. ${ }^{4}$ Recognition of corneal oedema is less about well defined structure as subtle display of colour and "haze."

It is felt by the authors that telemedicine is a wholly different experience from a simple telephone conversation and for many situations is capable of facilitating postoperative assessment with trained operators. H-261 video at $384 \mathrm{~K}$ (triple ISDN) is sufficient for anterior segment overall examination but is not sufficient for detailed corneal assessment. Other practitioners have used data rates up to four times faster for more detailed examination. $^{5}$

L F F Smith, J Bainbridge, J Burns, J Stevens, P Taylor, I Murdoch Moorfields Eye Hospital, City Road, London ECIV 2PD, UK

Correspondence to: Lindsey Smith 101506.1271@compuserve.com

Accepted for publication 2 September 2002

\section{References}

1 Murdoch I, Bainbridge J, Taylor P, et al. Postoperative evaluation of patients following ophthalmic surgery. J Telemed Telecare 2000;6(S1):84-6.

2 DeSutter E, DeMolder R, Gabirel P. Tele-ophthalmology. The TIME project: a tele-medicine project in the region Nord-Pas de Calais and Zuid-West Vlaanderen. Bull So Belge Ophtalmol 1994;252:37-42.

3 Li HK. Telemedicine and ophthalmology. Surv Ophthalmol 1999:44:61-72.

4 Solari SJ. Digital video and audio compression. London: McGraw-Hill, 1997.

5 Threlkeld AB, Fahd T, Camp M, et al.

Telemedical evaluation of ocular adnexa and anterior segment. Am J Ophthalmol 1999; 127:464-6.

\section{Inherited retinal dystrophy and asymmetric axial length}

The prenatal and postnatal development of the eye is determined by complex interactions between a number of genes, their products, and certain environmental factors. ${ }^{12}$ Since each eye is influenced by precisely the same processes as its fellow, mutations in regulatory genes usually lead to symmetric phenotypes. In this report, we describe two siblings of Asian ethnicity, born to unrelated parents with no family history of ocular disease, who have an unusual bilateral retinal dystrophy associated with very asymmetrical ocular growth.

\section{Case report}

Sib 1 was an 8 year old boy with epilepsy who had been born at term after an uneventfu pregnancy. Pendular nystagmus had been noted soon after birth and his visual acuity in each eye was 3/60; refraction -17.00 DS right, plano left. Anterior segment examination was with subretinal fibrosis. unremarkable with normal intraocular pressures. Examination of the right eye (Fig lA and $\mathrm{B}$ ) revealed generalised retinal pigment epithelial and choroidal atrophy, a macula "coloboma," sheathed and occluded retina vessels inferotemporally, and a shallow inferior longstanding retinal detachment with subretinal fibrosis. The left eye appeared similar; however there was no macula abnormality. By ultrasound, the axial length and ocular volume were $26.70 \mathrm{~mm}$ and $9.9 \mathrm{ml}$ right, 20.70 $\mathrm{mm}$ and $4.6 \mathrm{ml}$ left respectively.

Sib 2 was a 6 year old girl born at term with no significant past medical history. Her corrected visual acuity was 3/60 in each eye; refraction $-17.00 \mathrm{DS}$ right, plano left. Anterior segment examination was normal. Funduscopy of the right eye revealed a "macula coloboma," extensive retinal pigment epithelia and choroidal atrophy, intraretinal pigment migration and preretinal fibrosis. The appearances of the left eye were similar. No retinal detachment was noted. Axial lengths and ocular volumes were $26.1 \mathrm{~mm}$ and $9.4 \mathrm{ml}$ right, $20.7 \mathrm{~mm}$ and $4.6 \mathrm{ml}$ left, respectively.

Electrophysiology was performed on both children based on the ISCEV standards for adults, but initially using surface electrodes on the lower eyelids. No definite ERG response could be recorded from the emmetropic left eye of either child (even with high intensity stimulation or photopic flicker stimulation with averaging), a finding consistent with severe generalised dysfunction involving rod and cone photoreceptors. The electrical responses of both children's myopic fellow eye showed a milder degree of dysfunction: there were reduced b:a ratios in both scotopic and photopic responses which, together with the abnormal $30 \mathrm{~Hz}$ flicker ERGs, suggest a mid-retinal locus affecting postphototransductional cone and rod systems. The skin recordings obtained with surface
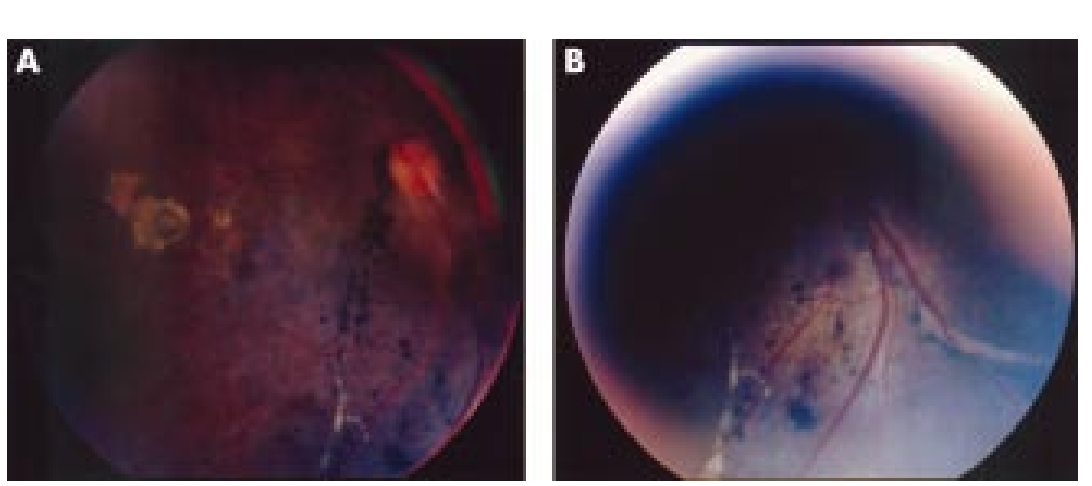

Figure 1 Colour photographs of right fundus of sib 1 (A) showing macular "coloboma," generalised retinal pigment epithelial and choroidal atrophy, and evidence of sheathed and occluded retinal vessels inferotemporally; (B) same eye, shallow inferior retinal detachment largement are carefully coordinated to equalise growth of fellow eyes in the quest for emmetropia. ${ }^{1}$ The differences observed in the two siblings described here reflect a decoupling of this developmental synchrony. It has been demonstrated that form deprivation in various species produces progressive axial growth and myopia of the postnatal eye. However, in both our sibs the ERG responses were much better preserved in the highly myopic right eye where, in addition, there was a low b:a ratio. Similar findings do not occur in myopia without retinal pathology. ${ }^{6}$

The bilateral symmetrical retinal dystrophy noted in both our patients suggests a genetic basis for the disease but a single genetic defect cannot explain the additional asymmetry of eye size and electrophysiological measurements. Most probably, the phenotype results from at least two separate events, a germline mutation in a retinal or retinal pigment epithelial specific gene leading to degeneration, thereby creating a susceptible background on which a second event could occur. This event, leading to the asymmetry of ocular volume, may be an environmental factor or a mutation in a second gene important in the regulation of eye growth. If this were a somatic rather than germline mutation it would explain the asymmetry of the disease.

P Francis, A G Robson, G Holder,

A Moore

Moorfields Eye Hospital, City Road, London ECIV 2PD, UK

P Francis, A Moore

Institute of Ophthalmology, University College London, London ECIV 9EL, UK

S Kaushal

University of Minnesota, Department of Ophthalmology and Institute of Human Genetics, 9-337 Phillips-Wangensteen Building, 516 Delaware Street SE, Minneapolis, MN 55455, USA

electrodes were confirmed under anaesthesia using gold foil corneal electrodes.

It is reasonable to conclude that these two siblings represent original probands with a novel inherited, probably autosomal recessive, retinal dystrophy. The particularly interesting feature of this disorder is the asymmetry of the axial lengths and ocular volumes of the eyes, rare in genetically determined ocular diseases. Indeed, we are aware of only one other report that identifies ocular asymmetry in association with retinal degeneration. Lafaut $e t ~ a l^{4}$ reported a single patient who had bilateral Stargardt's disease and unilateral myopia.

Normally, axial elongation and ocular en- 
Correspondence to: Professor A T Moore, Department of Molecular Genetics, Institute of Ophthalmology, University College London 11-43 Bath Street, London EC IV 9EL, UK tony.moore@ucl.ac.uk

Accepted for publication 3 September 2002

\section{References}

1 Brown N, Koretz J, Bron A. The development and maintenance of emmetropia. Eye $1999 ; 13: 83-92$

2 Crewther D. The role of photoreceptors in the control of refractive state. Prog Retina Eye Res 2000;19:42 1-57.

3 Fishman G, Birch D, Holder G, et al. Electrophysiologic testing in disorders of the retina, optic nerve and visual pathway. San Francisco: The Foundation of the American Academy of Ophthalmology, 2001.

4 Lafaut B, van Egmond J, de Laey J.

Asymmetric fundus flavimaculatus/Stargardt's disease, associated with unilateral myopia. In Ophthalmol 1995-6;19:253-5.

5 Wildsoet C, Schmid K. Optical correction of form deprivation myopia inhibits refractive recovery in chick eyes with intact or sectioned optic nerves. Vis Res 2000:40:3273-82

6 Perlman I, Meyer E, Haim T, et al. Retinal function in high refractive error assessed electroretinographically. Br J Ophthalmol 1984;68:79-84.

\section{Adenoma of ciliary pigment epithelium: a case series}

Adenoma of ciliary pigment epithelium is a rare tumour. Many are diagnosed retrospectively either after excision or enucleation, as malignant melanoma is suspected. ${ }^{1}$ We report a series of four patients found to have adenoma of ciliary pigment epithelium and discuss the clinical features and unusual behaviour of these neoplasms.

\section{Case reports}

We reviewed the histopathological reports in the ophthalmic pathology archive dating from 1980 to date and identified four patients who had the histopathological diagnosis of adenoma of ciliary pigment epithelium. We crosschecked the details with the clinical oncology database. We reviewed their notes for features that would help us to identify this ciliary body tumour clinically. The salient features of these patients are given in Table 1.

Patient 1 was reported elsewhere in 1994. He had a dark brown multinodular mass in the inferotemporal anterior chamber angle of the left eye. His tumour was a relatively smal but invasive lesion. Patient 2 was the only non-white patient with this condition in our series. Her tumour was an incidental finding when she presented to an ophthalmologist with allergic conjunctivitis. The tumour was small and dark brown. The tumour had invaded the anterior chamber angle and the root of the iris occupying one clock hour of the angle (Fig 1A, B, and C). Adenoma of the ciliary body was suspected, as she was non-white
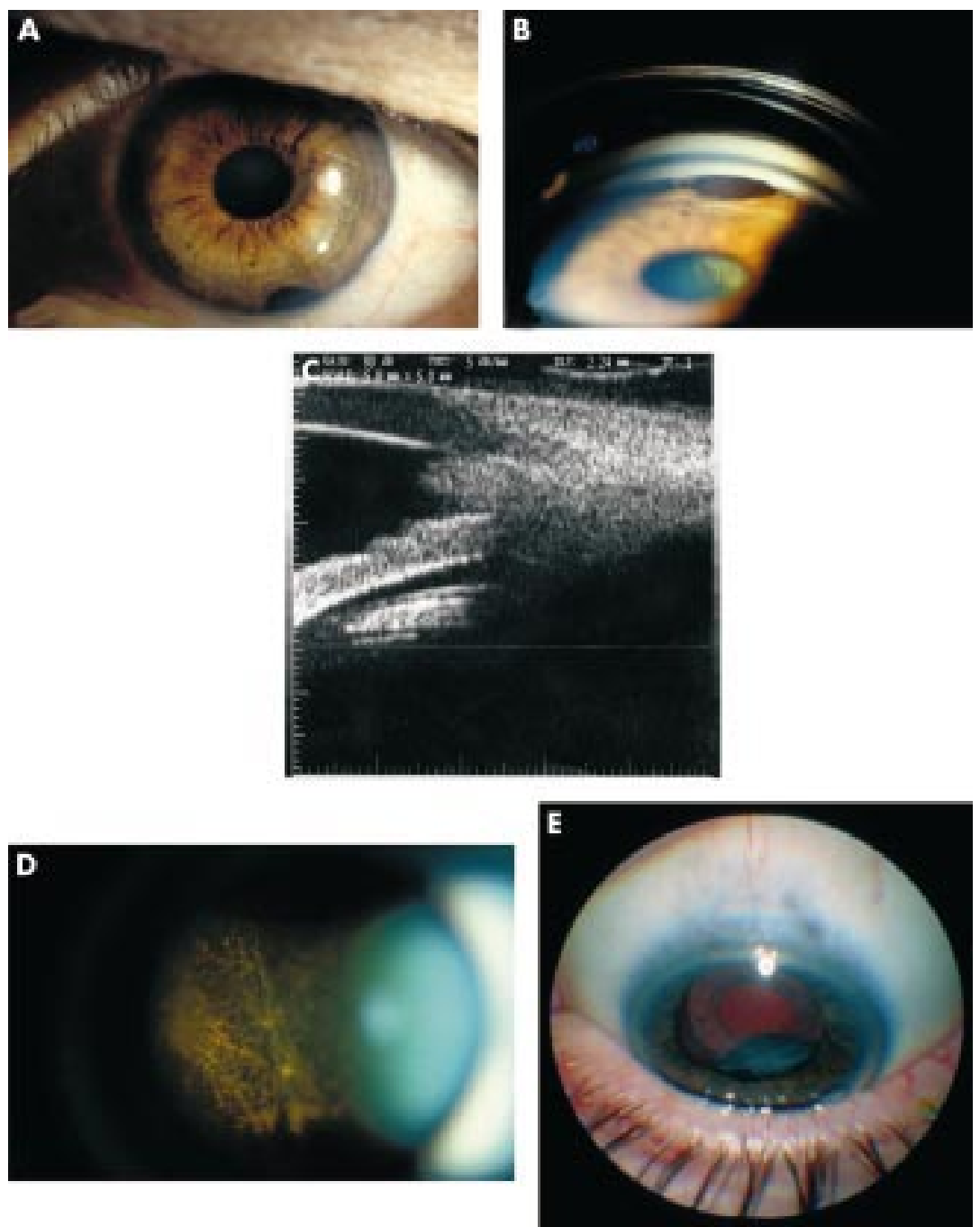

Figure 1 (A) A small ciliary body adenoma invading the angle in patient 2. (B) Gonioscopic view of the ciliary body adenoma (A) that had invaded the angle and the root of the iris, also showing the localised cataract through the pupil. (C) Ultrasound biomicroscopy of the adenoma of ciliary body shown in (A) and (B). (D) Pigment clumps in the vitreous in patient 3 . (E) Shows the adenoma of the ciliary body, the dark iris, and the trabeculectomy site in patient

and the degree of anterior chamber invasion appeared disproportionate to the size of the tumour.

Floaters and blurred vision were the presenting symptoms in patient 3 . The vitreous showed presence of pigment clumps and the extensive pigment dispersion made the media hazy (Fig ID). The tumour was a solid dark brown lesion arising from the ciliary body between the 12 and 1 o'clock meridians. The clinical differential diagnosis was between malignant melanoma and adenocarcinoma of the pigment epithelium of ciliary body.
Patient 4 was initially treated for acute angle closure glaucoma in another hospital. Trabeculectomy was performed to achieve control of intraocular pressure. Postoperatively, he was found to have a lesion behind the crystalline lens. He underwent phacoemulsification with intraocular lens implantation to improve visualisation of the lesion. A black ciliary body mass was seen (Fig IE) This prompted his referral to the oncology service in June 1999. Control of the intraocular pressure proved refractory even with additional medical treatment.

Table 1 Clinical details of the patients with adenoma of the pigment epithelium of ciliary body

\begin{tabular}{|c|c|c|c|c|c|c|c|c|}
\hline No & Age/sex/race & VA & Size $(\mathrm{mm})$ & Clinical features & Surgery & Recurrence & $\begin{array}{l}\text { Year of } \\
\text { diagnosis }\end{array}$ & Complication \\
\hline 1 & $40 / M / W$ & $6 / 5$ & $8 \times 7 \times 1$ & Angle invasion & Local resection & No & 1992 & $\mathrm{RD}$ repair \\
\hline 2 & $62 / F / A$ & $6 / 6$ & $5 \times 3 \times 1$ & Angle invasion, cataract & Local resection & No & 1996 & \\
\hline 3 & $65 / F / W$ & $6 / 18$ & $8 \times 6 \times 4$ & Sentinel vessel, pigment dispersion & Local resection & No & 1998 & $\mathrm{RD}$ repair \\
\hline 4 & $54 / M / W$ & $1 / 60$ & $5 \times 4 \times 4$ & Secondary glaucoma, pigment dispersion & Enucleation & No & 1999 & \\
\hline
\end{tabular}


Pigment dispersion was seen in patients 3 and 4 . This was mainly in the vitreous of patient 3 but in both the vitreous and the anterior segment of patient 4 . There was heterochromia of the iris in patient 4 . No angle invasion was seen in these two patients.

Other associated features were a localised cataract in patient 2 , tractional retinal detachment and secondary glaucoma in patient 4 Patient 3 had an episcleral sentinel vessel over the tumour. None of these patients had any history of ocular trauma or intraocular inflammation. Ultrasound biomicroscopy (Fig IC) helped us to evaluate these tumours in more detail.

The first three patients underwent local resection of the tumour in the form of iridocyclectomy under hypotensive anaesthesia. The last patient had enucleation as he opted to have the eye removed because of the poor visual prognosis for that eye as a result of secondary glaucoma, extensive pigment dispersion, and tractional retinal detachment.

Histopathologically, these tumours showed heavy pigmentation. Mitotic activity was absent or low. Invasion of ciliary muscle and the iris root was seen in patients 1 and 2 . Patient 3 had a cystic adenoma with cells forming gland-like structures around central cysts.

\section{Comment}

Our series highlights the paradoxical behaviour of adenoma of ciliary pigment epithelium. Smaller lesions invaded the angle and larger lesions caused extensive pigment dispersion although non-invasively. Angle invasion resulted in these tumours being seen and resulted in the presentation of patients $l$ and 2. Blurred vision due to pigment dispersion in the vitreous resulted in the presentation of patient 3. Angle closure glaucoma and pigment dispersion were the main features of patient 4. Shields et al presented a series of eight patients with adenoma of ciliary pigment epithelium and described their clinical features. In their series they found an association with cataract, vitreous haemorrhage, and neovascular glaucoma.

Pigment dispersion was seen in two of our patients. The presence of pigment clumps and extensive pigment dispersion in the vitreous of patient 3 (Fig 1D) is unique and has not been reported before. Chang $e^{2} \mathrm{al}^{3}$ in 1979 reported the presence of pigment in the retrolental space adjacent to the tumour in a case of adenoma of ciliary pigment epithelium. Extensive pigment dispersion in vitreous had been reported in malignant melanoma of the choroid ${ }^{4}$ but to our knowledge not in adenoma of ciliary pigment epithelium.

Secondary glaucoma from intraocular tumours is well known. In their survey of intraocular tumours causing secondary glaucoma Shields et al reported on 2704 eyes. Of the five adenomas of the ciliary body one was from ciliary pigment epithelium. None of these had secondary glaucoma. Of the ciliary body melanomas, $17 \%$ had secondary glaucoma. Angle closure was responsible for secondary glaucoma in $12 \%$ of the eyes with ciliary body melanoma. In their series in 1999 Shields et al' had one patient who had neovascular glaucoma secondary to adenoma of ciliary pigment epithelium. Patient 4 in our series presented with secondary angle closure glaucoma.

Malignant melanoma of ciliary body is known to invade the anterior chamber angle. Chang et $a l^{3}$ reported angle invasion in adenoma of the pigment epithelium of ciliary body. Shields et al $^{6}$ reported a patient in whom invasion of the iris stroma by an adenoma of ciliary pigment epithelium was documented with progressive growth. They initially suspected this to be a tumour of the iris but on later evaluation showed the origin from the ciliary body. The presenting feature in patients 1 and 2 in our series was similar, although the ciliary body origin was recognised initially. In patient 2 the diagnosis of adenoma of ciliary body was strongly suspected preoperatively, as the tumour that had invaded the angle was very small. Invasion of the angle by ciliary body melanomas usually does not occur until they have attained a larger size. Invasion of the angle has also been described in melanocytoma of the ciliary body. ${ }^{7}$ They too tend to be relatively larger when they invade the angle, unlike the adenomas that we described. Iris melanocytomas undergo central necrosis and cause pigment dispersion and glaucoma. ${ }^{8}$ However the necrotic centre is absent in adenomas.

One of our patients (patient l) had a sentinel vessel. Sentinel vessels are typically thought to be associated with malignancy. However, this is not always the case. Presence of a sentinel vessel indicates ciliary body involvement. Fine needle aspiration biopsy may be considered for aiding diagnosis of malignancy. However, its role in the diagnosis of these lesions may be limited. Absence of malignant cells does not always rule out the presence of malignancy.

Our study highlights the paradoxical behaviour of adenoma of the pigment epithelium of ciliary body that has not been emphasised before. Adenoma of the pigment epithelium of the ciliary body should be kept in mind if there is extensive pigment dispersion by larger tumours and invasion of the anterior chamber angle by relatively small tumours.

S Dinakaran, P A Rundle

Department of Ophthalmology, Royal Hallamshire Hospital, Glossop Road, Sheffield S10 2JF, UK

M A Parsons

Ophthalmic Sciences Unit

I G Rennie

Department of Ophthalmology and Orthoptics, University of Sheffield

Correspondence to: Mr S Dinakaran sdinakaran@yahoo.com

Accepted for publication 4 September 2002

\section{References}

Shields JA, Shields CL, Gunduz K, et al. Adenoma of the ciliary body pigment epithelium: the 1998 Albert Ruedemann, Sr, memorial lecture, part 1. Arch Ophthalmol 1999:117:592-7.

2 Rennie IG, Faulkner MK, Parsons MA Adenoma of the pigmented ciliary epithelium. Br J Ophthalmol 1994;78:484-5.

3 Chang M, Shields JA, Wachtel DL. Adenoma of the pigment epithelium of the ciliary body simulating a malignant melanoma. Am J Ophthalmol 1979;88:40-4.

4 El Baba F, Hagler WS, De la Cruz A, et al. Choroidal melanoma with pigment dispersion in vitreous and melanomalytic glaucoma. Ophthalmology 1988;95:370-7.

5 Shields CL, Shields JA, Shields MB, et al. Prevalence and mechanisms of secondary intraocular pressure elevation in eyes with intraocular tumours. Ophthalmology 1987;94:839-46.

6 Shields JA, Eagle RC, Shields $\mathrm{CL}$, et al. Progressive growth of benign adenoma of the pigment epithelium of the ciliary body. Arch Ophthalmol 2001;119:1859-61

7 LoRusso FJ, Boniuk M, Font RL.

Melanocytoma (magnocelluler nevus) of the ciliary body: Report of 10 cases and review of literature. Ophthalmology 2000;107:795800

8 Fineman MS, Eagle RC, Shields JA, et al. Melanocytomalytic glaucoma in eyes with necrotic iris melanocytoma. Ophthalmology 1998; 105:492-6.

Phenylephrine $2.5 \%$ and $10 \%$ in phacoemulsification under topical anaesthesia: is there an effect on systemic blood pressure?

Phenylephrine $10 \%$ leads to a faster and more pronounced mydriasis but cardiovascular effects like hypertension and arrhythmias have been reported. In a young healthy adult the upper limit of safety for intravenous administration of phenylephrine is $1.5 \mathrm{mg}^{1}$ and Kumar et $\mathrm{al}^{2}$ had found phenylephrine plasma levels after administration of topical 10\% viscous solution to their patients to be 1.842$11.526 \mathrm{ng} / \mathrm{ml}$ after 20 minutes while topical $2.5 \%$ aqueous solution produced plasma levels of $0-1.720 \mathrm{ng} / \mathrm{ml}$ after 20 minutes. They concluded that the mean pressure tended to be higher with the $10 \%$ viscous solution.

Chin et al $^{3}$ in their study on 89 patients, concluded that significant hypertensive effects can arise after topical phenylephrine; however, no significant difference between the two groups $(2.5 \% \vee 10 \%)$ was shown. Symons et al ${ }^{4}$ reported no significant change in the mean systolic and diastolic blood pressure in 126 patients receiving 10\% phenylephrine. Malhotra et al in their study on 54 cases showed no difference in systemic cardiovascular effects of either the $2.5 \%$ or the $10 \%$ concentration.

\section{Methods}

We carried out a prospective randomised and double masked study on 53 patients undergoing phacoemulsification under topical anaesthesia (Amethocaine $0.1 \%$ and Marcaine $0.75 \%$ ) and no exclusion of cases with hypertension, heart failure, or diabetes was made. All patients received one drop of each of tropicamide $1 \%$, cyclopentolate $1 \%$, and Voltarol $0.1 \%$. Phenylephrine drops, either $2.5 \%$ or $10 \%$, were administered in three doses starting half hour before surgery at 5 minute intervals. All patients had their blood pressure measured before dilatation and in the anaesthetic room preoperatively then postoperatively.

\section{Results}

The study included 49 cases aged 52-91, 24 cases were known to have cardiovascular problems and seven were also diabetic. Comparison of the blood pressure changes before

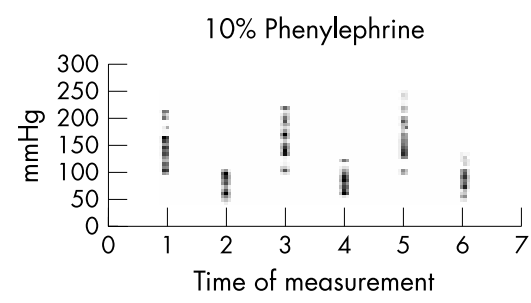

Figure 1 Blood pressure $(\mathrm{mm} \mathrm{Hg}$ ) with phenylephrine $2.5 \%$. Numbers 1 and $2=$ systolic and diastolic reading preanaesthetic; 3 and 4 = systolic and diastolic reading in the anaesthetic room; 5 and $6=$ systolic and diastolic reading in recovery. 
Table $1 \quad t$ Test $2.5 \%$ and $10 \%$ (normotesives and hypertensives)

\begin{tabular}{llll}
\hline & Mean & SD & Significance* $^{*}$ \\
\hline Normotensive/sys & -12.44 & 19.08 & 0.86 \\
Normotensive/diast & 2.88 & 16.64 & 0.61 \\
Hypertensive/sys & 14.16 & 28.36 & 0.27 \\
Hypertensive/diast & -4.16 & 14.00 & 0.49
\end{tabular}

Two tailed $t$ test, comparing the $2.5 \%$ group and $10 \%$ group both hypertensive and normotensive patients.

${ }^{*} \mathrm{p}=0.05$

dilatation and in the anaesthetic room preoperatively in the $2.5 \%$ group (Fig l showed a mean rise in systolic BP of $22 \mathrm{~mm} \mathrm{Hg}$ $(p=0.003)$ in the normotensive group. In the hypertensive group all patients recorded statistically significant rises in systolic and diastolic BP (respectively $\mathrm{p}=0.010, \mathrm{p}=0.009$ ) In the $10 \%$ group (Fig 2, 10 patients in the normotensive group showed a mean rise in systolic $\mathrm{BP}$ of $34.4 \mathrm{~mm} \mathrm{Hg}(\mathrm{p}=0.001)$ and 10.5 $\mathrm{mm} \mathrm{Hg}$ in diastolic BP $(\mathrm{p}=0.077)$. In the hypertensive group six patients recorded a rise in systolic BP with a mean of $22.8 \mathrm{~mm} \mathrm{Hg}$ $(p=0.015)$ and a diastolic rise with a mean of $16.8 \mathrm{~mm} \mathrm{Hg}(\mathrm{p}=0.033)$ (Table 1 ) (Figs 3 and $4)$.

\section{Comment}

Our study showed that patients in both groups of phenylephrine doses experienced a rise in systolic blood pressure which was statistically significant; the mean of which is higher in the $10 \%$ group. The maximal systolic blood pressure rise is around 10-20 minutes after administration, which corresponds to the time of maximal plasma levels of phenylephrine as demonstrated by other authors, ${ }^{5}$ but the paired $t$ test failed to show any significance between the results of the groups of either concentration. Postoperative results showed some elevations in systolic and diastolic BP but weren't statistically significant. Using Altman's normogram the study was limited in its power. Although the aim of this study was not designed to investigate the effect of anxiety on systemic blood pressure, this element should be taken into consideration since it is known to elevate the systolic blood pressure. We have also used topical anaesthesia so that adrenaline 1:200000, which is always included in local anaesthesia, is excluded which might cause elevation of the blood pressure although the concentration is too low for any significant systemic effect.

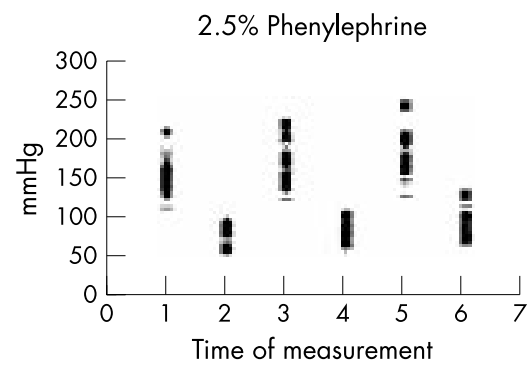

Figure 2 Blood pressure $(\mathrm{mm} \mathrm{Hg})$ with phenylephrine $10 \%$. Numbers 1 and $2=$ systolic and diastolic reading preanaesthetic; 3 and $4=$ systolic and diastolic reading in the anaesthetic room; 5 and $6=$ systolic and diastolic reading in recovery.

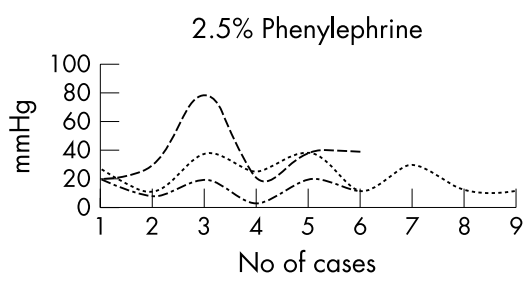

Figure 3 Blood pressure $(\mathrm{mm} \mathrm{Hg})$ with phenylephrine $2.5 \%$ The mean changes to systolic and diastolic BP.

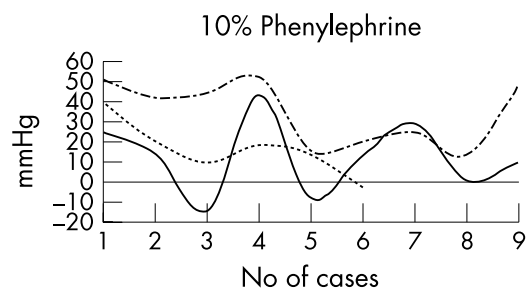

Figure 4 Blood pressure $(\mathrm{mm} \mathrm{Hg})$ with phenylephrine 10\% The mean changes to systolic and diastolic BP.

We therefore recommend the routine use of the $2.5 \%$ phenylephrine in ophthalmic surgery and only use $10 \%$ solution for cases where the lower concentration may not be as effective.

N B Kenawy, M Jabir

Department of Ophthalmology, Rotherham Genera Hospital, Moorgate Road, Oakwood, Rotherham S60 2UD, UK

Correspondence to: $\operatorname{Dr} N$ Kenawy nkenawy@yahoo.co.uk

Accepted for publication 4 September 2002

\section{References}

1 Fraunfelder FT, Scafidi AF. Possible adverse effects from topical ocular 10\% phenylephrine. Am J Ophthalmol 1978;85:447-53

2 Kumar V, Schoenwald RD, Chien DS, et al. Systemic absorption and cardiovascular effets of phenylephrine eye drops. Am J Ophthalmol 1985;99:180-4.

3 Chin KW, Law NM, Chin MK. Phenylephrine drops in ophthalmic surgery: a clinical study on cardiovascular effects. Med J Malaysia 1994:49:158-63.

4 Symons RCA, Walland M, Kaufman DV. Letter to the editor. Eye 1997;11:946-7.

5 Malhotra R, Banerjee G, Brampton W, et al. Comparison of the cardiovascular effects of $2.5 \%$ phenylephrine and $10 \%$ phenylephrine during ophthalmic surgery. Eye $1998 ; 12: 973-5$.
Effect of preoperative detection of photoreceptor displacement on postoperative foveal findings in eyes with idiopathic macular hole

In idiopathic macular hole formation, Gass hypothesised that macular holes enlarge with displacement of the photoreceptors without tissue loss around the fovea. Jensen and Larsen $^{2}$ developed binocular kinetic perimetry that could evaluate local retinal photoreceptor displacement and also confirm centrifugal photoreceptor displacement away from the foveola in eyes with a macular hole. Using the binocular perimetry technique and scanning laser ophthalmoscope microperimetry, we confirmed that the patients with a unilateral macular hole with preoperative photoreceptor displacement had better postoperative visual function when compared to patients without preoperative photoreceptor displacement. ${ }^{3}$ We also previously reported that the postoperative foveal findings were correlated with the postoperative visual function in eyes with macular hole. ${ }^{4}$

The purpose of the present study was to investigate whether or not detecting photoreceptor displacement preoperatively affects the postoperative foveal findings in eyes with an idiopathic macular hole.

\section{Methods and results}

Fifteen patients ( 12 women, three men; mean age 62 (SD 5) years) with a unilateral idiopathic macular hole that resolved after vitreous surgery were examined. All had undergone surgery at our institution. Eleven eyes were classified as having a stage 3 hole, four stage 2, and one stage 4 . The best corrected visual acuity (VA) levels in the unaffected eyes were 0.7 or better, and no patients had ocular diseases except for mild cataract.

To detect photoreceptor displacement in eyes with the disease preoperatively, we performed binocular kinetic perimetry. ${ }^{23}$ The anatomical status of the repaired macular holes was assessed 3 months after the operation using optical coherence tomographic equipment (OCT 2000, Humphry Instrument, division of Carl Zeiss, San Leandro, CA, USA). Good postoperative foveal findings were defined as the presence of a foveal depression, as previously reported by Imai and associates ${ }^{5}$ (Figs 1 and 2).

Photoreceptor displacement was detected in 11 of the 15 (73\%) patients preoperatively. Good postoperative foveal findings were observed in nine of the $11(82 \%)$. Photoreceptor displacement was detected preoperatively in all nine patients. The prevalence of good postoperative foveal findings was significantly higher in patients in whom photoreceptor

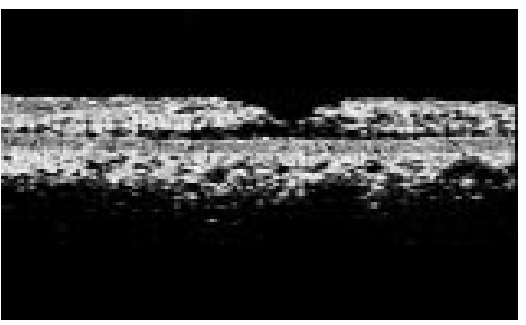

Figure 1 Good postoperative foveal findings observed with optical coherence tomography. A foveal depression is observed. 


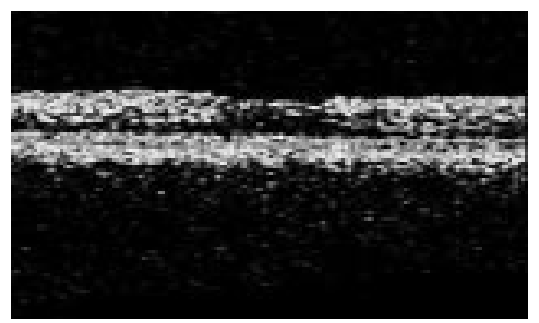

Figure 2 Bad postoperative foveal findings observed with optical coherence tomography. A foveal depression is not observed.

displacement $(82 \%, 9 / 11)$ was detected preoperatively than in those in whom displacement was not detected $(0 \%, 0 / 4) \quad\left(p=0.01, \chi^{2}\right.$ test with Yates's correction). The mean preoperative VA tended to be better and the mean VA measured 3 months postoperatively was significantly better in patients in whom photoreceptor displacement was detected preoperatively ( 0.15 and 0.79 , respectively) than in those whom it was not detected $(0.08$ and 0.25 , respectively) ( $\mathrm{p}=0.06$ and $\mathrm{p}=0.001$, respectively, unpaired $t$ test). Visual acuities were converted to the logarithm of the minimum angle of resolution (logMAR) for statistical analysis.

\section{Comment}

Jensen and Larsen $^{2}$ reported that in two macular hole patients with the longest duration of symptoms, photoreceptor displacement was not detected. The reason why patients with a macular hole with longer duration of symptoms did not have photoreceptor displacement might be that there was more damage to the displaced photoreceptors A longer disease duration probably induced functional damage to the displaced photoreceptors, and consequently no photoreceptors are displaced from the fovea. We also reported that the detection of photoreceptor displacement preoperatively should affect postsurgical visual function, and photoreceptor damage might occur in eyes in which photoreceptor displacement was not detected preoperatively, resulting in worse postoperative visual function. ${ }^{3}$

Our results demonstrated that in patients with a macular hole in whom photoreceptor displacement was detected preoperatively, the postoperative foveal findings and visual acuities were better when compared to patients in whom displacement was not detected preoperatively. It was also reported that better anatomical foveal recovery in eyes after macular hole surgery resulted in better improvement of postoperative visual function. ${ }^{4}$ Although limitations of this study are based in its sample size, we think that a degree of preoperative photoreceptor damage influences not only postoperative visual function but also anatomical recovery.

The authors have no proprietary interest in any instruments used in this study.

T Hikichi, N Kitaya, S Konno, J Takahashi, F Mori, A Yoshida Department of Ophthalmology, Asahikawa Medical College, Asahikawa, Japan
Correspondence to: Taiichi Hikichi, MD Department of Ophthalmology, Asahikawa Medical College, 2-1 Midorigaoka-higashi, Asahikawa 078-8510, Japan; hikichi@asahikawa-med.ac.jp

Accepted for publication 5 September 2002

\section{References}

1 Gass JDM. Reappraisal of biomicroscopic classification of stages of development of a macular hole. Am J Ophthalmol 1995; 1 19:752-9.

2 Jensen $O M$, Larsen $M$. Objective assessment of photoreceptor displacement and metamorphopsia. a study of macular holes. Arch Ophthalmol 1998;1 16:1303-6.

3 Hikichi T, Kitaya N, Takahashi J, et al. Association of preoperative photoreceptor displacement and improved central scotoma after idiopathic macular hole surgery. Ophthalmology (in press)

4 Hikichi T, Ishiko S, Takamiya A, et al. Scanning laser ophthalmoscope correlations with biomicroscopic findings and foveal function after macular hole closure. Arch Ophthalmol 2000;118: 193-7.

5 Imai $\mathbf{M}$, lijima H, Gotoh T, Tsukahara S. Optical coherence tomography of successfully repaired idiopathic macular holes. Am J Ophthalmol 1999;128:621-7.

\section{Nodular scleritis in a patient with sarcoidosis}

Sarcoidosis is an immune mediated disease that may affect any organ. Scleral involvement has rarely been described with sarcoidosis. ${ }^{1-3}$ We report on a patient with unilateral nodular anterior scleritis who was found to suffer from sarcoidosis. Here, the clinical and histopathological features are described.

\section{Case report}

A 53 year old white woman had persistent moderate tenderness in her left eye that lasted for several weeks. Visual acuity was 20/20 in both eyes. The slit lamp appearance of the right eye was unremarkable. A scleral nodule in the inferior nasal quadrant was found in the left eye (Fig l), and a moderate tenderness was determined in this area. The intraocular pressures were within normal ranges. On ophthalmoscopy, the posterior segment of both eyes was normal. The ultrasound images did not indicate posterior scleritis.

The medical history was remarkable for an episode of hepatitis A 20 years ago, and the patient suffered from exercise dependent dyspnoea, night sweats, and repeated headaches

An extensive examination for associated systemic diseases was performed, including serological tests for syphilis, CRP, ESR, ANCA RF, CIC, ANA, and PPD tests: all were within normal ranges and consultant examinations by the internal medicine, rheumatology, neurology, and ENT departments were performed. The chest $x$ ray examination revealed a

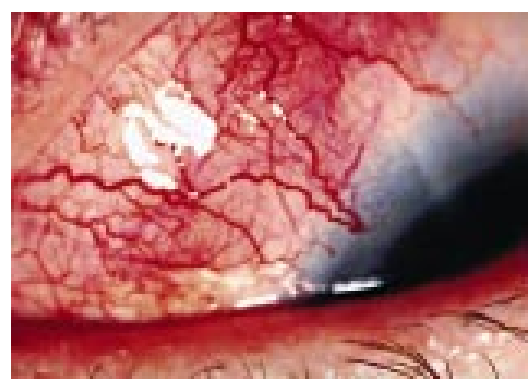

Figure 1 Scleral nodule of the left eye with tenderness in a patient with sarcoidosis.

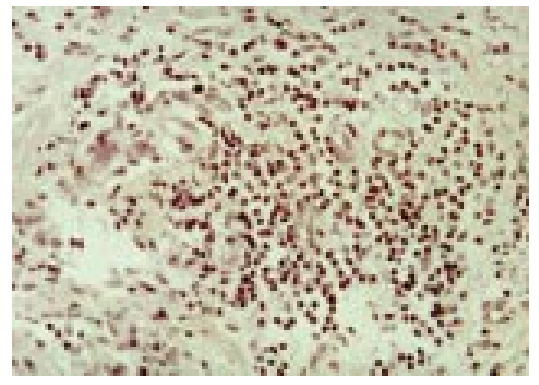

Figure 2 Histopathology of a scleral nodule in a patient with sarcoidosis. The scleral tissue with oedema and vessel dilatation, perivascular lymphocytic cell infiltration with non-caseating granuloma-like cell accumulation, some histiocytes and giant cells. Haematoxylin and eosin staining, magnification, $\times 200$.

bilateral hilar lymphadenopathy and basal interstitial pulmonary infiltration typical of sarcoidosis stage 2 . In the body plethysmography, a mild restriction and a moderately reduced diffusion capacity was determined. The bronchoalveolar lavage revealed an increased proportion of $\mathrm{CD}^{3}+\mathrm{T}$ cells and an increased CD4/CD8 ratio, consistent with active pulmonary sarcoidosis. The level of angiotensin converting enzyme was $51.3 \mathrm{U} / \mathrm{l}$ (normal, 8-52) in the high normal range. The magnetic resonance images revealed an increased enhancement and thickening of the inferior nasal part of the sclera of the left eye.

A biopsy was taken from the scleral nodule under peribulbar anaesthesia. Histopathological studies on the paraffin embedded tissue that was performed by the pathologists revealed a perivascular lymphocytic cell infiltration, with non-caseating granuloma-like cell accumulation (Fig 2). Some histiocytes and very few giant cells were found. The scleral tissue was oedematous and the vessels were dilated, but necrosis, vasculitis or malignant cell configurations were absent. Additionally, Ziehl-Neelson and Gonori's silver methaminamine stains excluded the possibility of causative infections.

Treatment with oral prednisone with an initial dosage of $1 \mathrm{mg} / \mathrm{kg}$ was performed. The corticosteroid dosage was tapered within 6 weeks, and was maintained at $20 \mathrm{mg}$. Under this regimen, the pain and the scleral nodule resolved immediately, and the ACE level fell to $24 \mathrm{U} / 1$ (normal).

\section{Comment}

Scleral involvement has been previously reported in a few patients with sarcoidosis. In a series of 537 patients with histologically proved sarcoidosis, ${ }^{3}$ scleral plaques anterior to the equator have been found in four cases, and this was seen in the acute stage of disease and in association with erythema nodosum and bihilar lymphadenopathy. In another series by Jabs and Johns, ${ }^{2}$ within a group of 183 patients with chronic sarcoidosis, scleral involvement was detected in one patient. However, the clinical course and histopathological appearances have not been described previously. Posterior scleritis has been seen only rarely with sarcoidosis

In our patient, the sparse systemic symptoms made the diagnosis difficult and, therefore, scleral biopsy was done in order to rule out infections or malignancies and to disclose the histopathological evidence for sarcoidosis. Although a classic non-caseating granuloma 
has not been found in our patient, a granuloma-like perivascular cell infiltration was seen, consisting primarily of lymphocytes, some histiocytes, and very few giant cells, which are typical for sarcoidosis. To the best of our knowledge, this is the first histopathological description of a sarcoid lesion in the sclera. The mainstay of treatment for sarcoidosis is corticosteroids, and the scleritis responded in our patient.

\section{Acknowledgements}

The authors thank Professor Dr Annette FisselerEckhof, Department of Pathology, Zentralklinik Emi von Behring in Berlin and Professor Dr Christian Witting, Department of Pathology, Clemens Hospital, Muenster for the histopathological evaluation of the tissue specimens.

A Heiligenhaus, D Michel, J M Koch Department of Ophthalmology, St Franziskus Hospital, Muenster, Germany

Correspondence to: Arnd Heiligenhaus, MD Department of Ophthalmology, St Franziskus Hospital, Hohenzollernring 74, 48145 Muenster, Germany; arnd.heiligenhaus@t-online.de

Accepted for publication 5 September 2002

\section{References}

1 Dodds EM, Lowder CY, Barnhorst DA, et al. Posterior scleritis with annular ciliochoroidal detachment. Am J Ophthalmol 1995; 120:677-9.

2 Jabs DA, Johns CJ. Ocular involvement in chronic sarcoidosis. Am J Ophthalmol 1986; 102:297-301.

3 James DG, Neville E, Langley DA. Ocular sarcoidosis. Trans Ophthalmol Soc UK 1976;96:133-9.

\section{Panophthalmitis following contact diode laser cyclophotocoagulation in a patient with failed trabeculectomy and trabeculotomy for congenital glaucoma}

Diode laser trans-scleral cyclophotocoagulation (TSCPC) is a well accepted method for the management of patients with refractory glaucoma. A lasting decrease in IOP has been reported in about two thirds of eyes with severe, medically uncontrolled glaucoma following contact TSCPC using G-probe delivery, with preservation of visual acuity. ${ }^{12}$ Although the procedure is considered safe, ${ }^{3}$ complications have been reported. ${ }^{15}$ Here, we report the first case, to the best of our knowledge, of panophthalmitis following contact diode laser cyclophotocoagulation using the G-probe in a patient with failed trabeculectomy and trabeculotomy for congenital glaucoma.

\section{Case report}

An 18 year old male patient presented to our emergency service with a 4 day history of pain, redness, and periorbital swelling in the right eye, accompanied by poor vision. One week earlier he had undergone 360 degree diode laser trans-scleral cyclophotocoagulation using contact G-probe in the right eye for uncontrolled glaucoma. He had thrice undergone filtering surgeries in both eyes for congenital glaucoma since 1985. During the last trabeculectomy performed in 1996, intraoperative mitomycin C $(0.2 \mathrm{mg} / 100 \mathrm{ml}$ applied for 3 minutes beneath the scleral flap) had also been used. But it failed in the right eye and the patient had developed a painful blind eye.
His visual acuity was no light perception in the right eye and 20/60 in the left. There was right sided periorbital oedema, restricted motility, and purulent discharge with matting of the eyelashes. Rupture of the globe with prolapse of the iris was evident along the superior limbus. In the left eye the bleb was well formed, and the IOP (Goldmann applanation) was $12 \mathrm{~mm} \mathrm{Hg}$. The optic disc showed a cup disc ratio of 0.4 with temporal pallor.

A diagnosis of panophthalmitis of the right eye was made. As no response to intravenous antibiotic treatment was observed over the next 48 hours, evisceration was undertaken with the patient's informed consent. Staphylococcus epidermidis was grown on culture.

\section{Comment}

Its efficacy notwithstanding, diode laser cyclophotocoagulation has been associated with complications, although less frequent than with other cyclodestructive procedures. Conjunctival burns, corneal decompensation, neurotrophic corneal defects, uveitis, IOP spikes, phthisis $(0.5 \%)$, chronic hypotony ( $1 \%)$, macular pucker $(0.5 \%)$, intraocular haemorrhage $(0.5 \%)$, visual loss, and malignant glaucoma have all been reported. ${ }^{15}$ Possible correlation of outcome with perilimbal pigmentation, and the hearing of audible "pop," especially in patients with dark brown irides, ${ }^{4}$ has been suggested.

Scleral thinning is a recognised risk factor for complications, but scleral perforation following this procedure has been reported earlier in one patient only. ${ }^{9}$ This patient had scleral thinning following previous cataract surgery. Possibly, the sharp probe edge had cut conjunctival vessels causing bleeding and contamination of the probe tip. Thin adherent debris was then carbonised allowing the laser tip temperature to rise to $300^{\circ} \mathrm{C}$, sufficient to cause scleral perforation. This report led to redesigning of the probe tip to protect the vascular structures from its sharp edges.

Our patient was treated as part of a standard protocol using the modified $G$ probe, and bleeding did not occur. The perforation could have resulted from mechanical pressure, or the effect of the laser on the thinned out sclera, which the patient probably had as a result of buphthalmos and previous ocular surgery. ${ }^{9}$ There are no known "corrective factors" to utilise in eyes with severe scleral thinning, and if treatment is absolutely necessary, a $40 \%$ lower energy should be used, ${ }^{10}$ and areas of thinning and possible wound dehis cence, such as the bleb, should be avoided. We emphasise caution in undertaking contact diode laser trans-scleral cyclophotocoagulation in operated eyes with thin sclera.

P Venkatesh, M Gogoi, R Sihota, H Agarwal

Dr Rajendra Prasad Centre for Ophthalmic Sciences, All India Institute of Medical Sciences,

New Delhi, India

Correspondence to: Dr Pradeep Venkatesh, Dr Rajendra Prasad Centre for Ophthalmic Sciences All India institute of Medical Sciences, Ansari Nagar, New Delhi 110029 , India; venkyprao@yahoo.com

Accepted for publication 5 Spetember 2002

\section{References}

Bloom PA, Tsai JC, Sharma K, et al "Cyclodiode" trans-scleral diode laser cyclophotocoagulation in the treatment of advanced refractory glaucoma. Ophthalmology 1997;104:1508-20.

2 Kosoko O, Gaasterland DE, Pollack IP, et al. Long-term outcome of initial ciliary ablation with contact diode laser transscleral cyclophotocoagulation for severe glaucoma. The Diode Laser Ciliary Ablation Study Group. Ophthalmology 1996;103:1294-302.

3 Becker M, Funk J. Diode laser cyclophotocoagulation as the primary surgical intervention in glaucoma [article in German] Ophthalmologe 2001;98:1145-8.

4 Martin KR, Broadway DC. Cyclodiode laser therapy for painful, blind glaucomatous eyes. Br J Ophthalmol 2001:85:474-6.

5 Yap-Veloso MI, Simmons RB, Echelman DA, et al. Intraocular pressure control after contact transscleral diode cyclophotocoagulation in eyes with intractable glaucoma. J Glaucoma 1998;7:319-28.

6 Azuara-Blanco A, Dua HS. Malignant glaucoma after diode laser cyclophotocoagulation. Am J Ophthalmol 1999; 127: 467-9.

7 Hennis HL, Stewart WC. Semiconductor diode laser transscleral cyclophotocoagulation in patients with glaucoma. Am J Ophthalmol 1992;113:81-5.

8 Johnson SM. Neurotrophic corneal defects after diode laser cycloablation. Am J Ophthalmol 1998;126:725-7

9 Sabri K, Vernon SA. Scleral perforation following trans-scleral cyclodiode. Br J Ophthalmol 1999:83:502-3

10 Palmer DJ, Cohen J, Torczynski E, et al. Transscleral diode laser cyclophotocoagulation on autopsy eyes with abnormally thinned sclera. Ophthalmic Surg Lasers 1997:28:495-500.

\section{Bilaminar interepithelial bodies within fingerprint dystrophy-like changes in bilateral iridocorneal endothelial syndrome}

In most cases the iridocorneal endothelial (ICE) syndrome affects women unilaterally and shows endothelial degeneration, thickening of Descemet's membrane, iris atrophy, and glaucoma. The spectrum of the ICE syndrome includes the Chandler's syndrome, the essential iris atrophy, and the Cogan-Reese syndrome. We present a unique case of an ICE syndrome, which we would subclassify as Chandler's syndrome, with concomitant fingerprint dystrophy and multiple interepithelial bilaminar bodies within the fingerprintlike striae.

\section{Case report}

Ten years earlier a now 45 year old patient presented with a bilateral ICE syndrome and fingerprint dystrophy. On slit lamp microscopy the epithelial layer showed fingerprint lines, while the endothelial layer had a "hammered" appearance. Iris atrophy, corectopia, ectropium uveae and anterior synechiae were obvious (Fig 1A) and progressive in both eyes, nevertheless the intraocular pressure and the visual acuity were normal. Eight years later both corneas developed oedema (Fig 1B) and the left eye displayed cataract with reduction of visual acuity from 1.0 to 0.25 and 0.9 to 0.7 in the left and right eye, respectively. Combined perforating keratoplasty and extracapsular cataract extraction were performed on the left eye in June 1998. None of the patient's family members had a similar condition.

The histological examination of the paraffin embedded corneal specimen revealed fingerprint-like striae containing small basophilic deposits between the cells (Fig 2A). The van Kossa stain for calcium was negative and no hydroxyapatite crystals were seen. At the ultrastructural level the deposits were found to be round and bilaminar showing an electron dense core in the centre (Fig 2B). Some of the deposits coalesced to form oval 

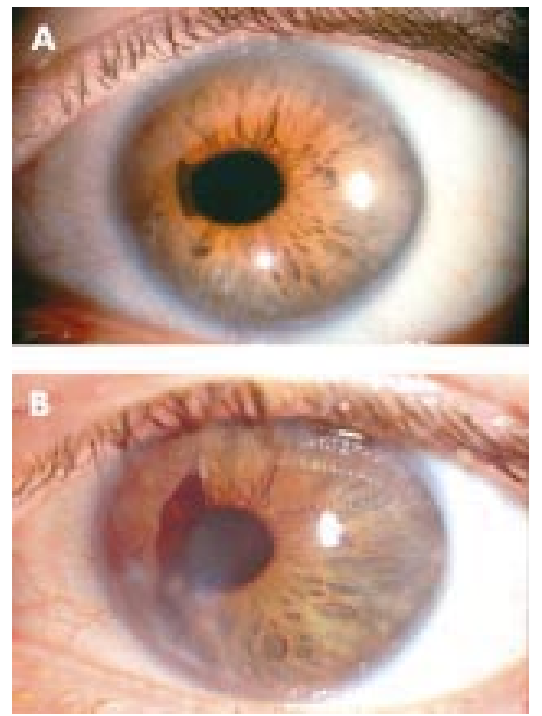

Figure 1 (A) The left eye in 1990 with iris atrophy, corectopia, ectropium uveae, and anterior synechiae. (B) The left eye in 1998 with progression of the pathological changes.
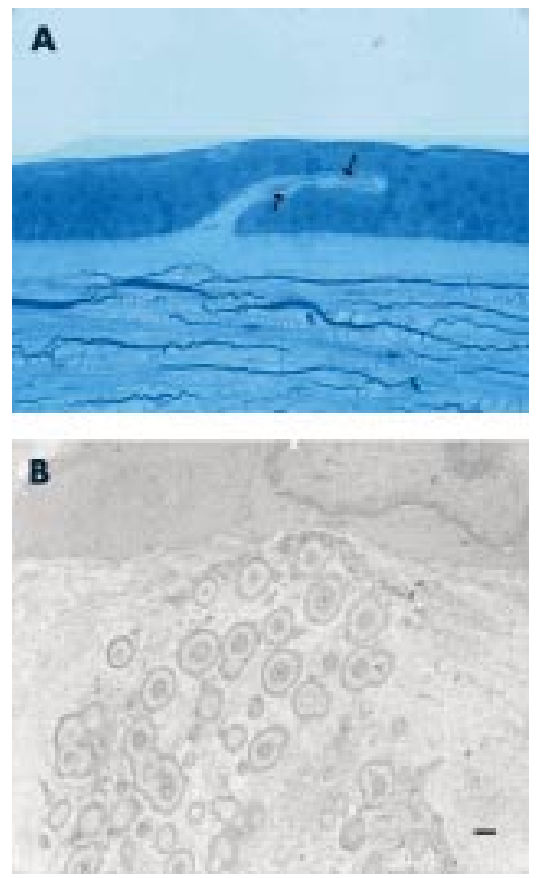

Figure 2 (A) Fingerprint-like stria containing small basophilic deposits between the cells (toluidine blue, $\times 400$ ). (B) The cytoplasm of the epithelial cells was normal without deposits in relation to the cell membranes (uranyl acetate, lead citrate, bar $=250 \mathrm{~nm})$.

structures. The cytoplasm of the adjacent epithelial cells was normal without deposits in relation to the cell membranes. Descemet's membrane was not thickened, the endothelial cells possessed microvilli, their mitochondria were degenerated, and intercellular interdigitations were pronounced.

\section{Comment}

We consider our case as one of Chandler's syndrome, which is part of the spectrum of the ICE syndrome, owing to obvious morphological changes of the iris despite non-specific endothelial changes. The striking features of Chandler's syndrome are corneal endothelial dystrophy and subsequent oedema. ${ }^{1}$ Corectopia, glaucoma, and iris atrophy are less compared to the two other ICE syndromesthat is, the essential iris atrophy and the irisnaevus syndrome, possibly owing to differences in endothelial proliferative activity. ${ }^{2}$

Our case is unique in several aspects. Firstly, our patient is a man and is affected bilaterally. Most often women are affected unilaterally by ICE syndrome, nevertheless an exception of essential iris atrophy with bilateral changes have been described

Secondly, an epithelial dystrophy-namely, a fingerprint dystrophy, is present in addition to the ICE associated changes. To our knowledge this association has not been described in the literature before.

Thirdly, the fingerprint striae contain bilaminar deposits with an electron dense core. Several types of deposits have been described in association with epithelial dystrophies. Patches of "unknown substance" were noticed in fingerprint dystrophy along basal plasmalemmas of the basal epithelial cells with no similarity to the bilaminar structures described here. ${ }^{4}$ Broderick et al mentioned intercellular dense oblong bodies which were embedded in condensed matrix and were much smaller than the deposits in our case. ${ }^{5}$ In a cornea with a Meesmann dystrophy intraepithelial "peculiar electron dense substance" were shown, also with a totally different appearance compared to that seen in the fingerprint striae of the specimen we present here. In a patient with ocular tumoral calcinosis, nodules from the palpebral conjunctiva contained calcified "spherules," which show some similarity to ournevertheless, uncalcified-deposits. Our deposits were located within the fingerprint striae, close to the epithelium. It seems to be obvious that the epithelial cells must have produced those bilaminar bodies, since no other cell type was present nearby, but there was no evidence of extrusion from the basal cells.

Our case shows that ICE syndrome can occur bilaterally in men, and can be associated with a fingerprint-like dystrophy. Further studies should be carried out to confirm our electron microscopical observation of bilaminar deposits within fingerprint-like striae and directed towards an analysis of their chemical composition of the extracellular material and origin.

\section{Acknowledgements}

We thank Mrs Annegret Mattes and Mrs Dorothy A Aitken for providing electron microscopic assistance.

This case was presented as a poster at the meeting of the Association for Research and Vision in Ophthalmology in Fort Lauderdale in May 2001.

C Auw-Haedrich Universitäts-Augenklinik Freiburg, Germany

U Sengler Universitäts-Augenklinik Düsseldorf, Germany

W R Lee

Department of Pathology, University of Glasgow,
Scotland, UK

Correspondence to: Dr Claudia Auw-Haedrich Universitäts-Augenklinik, Killianstrasse 5, D-79106 Freiburg, Germany; auw@aug.ukl.uni-freiburg.de

Accepted for publication 9 September 2002

\section{References}

1 Chandler PA. Atrophy of the stroma of the iris: esndothelial dystrophy, corneal edema, and glaucoma. Am J Ophthalmol 1956;41:607-15.

2 Campbell DG, Shields MB, Smith TR. The corneal endothelium and the spectrum of essential iris atrophy. Am J Ophthalmol 1978;86:317-24.

3 Kaiser-Kupfer M, Kuwabara T, Kupfer C. Progressive bilateral essential iris atrophy. Am J Ophthalmol 1977;83:340-6.

4 Rodriguez MM, Fine BS, Laibson PR, et al. Disorders of the corneal epithelium. A clinicopathologic study of dot, geographic, and fingerprint patterns. Arch Ophthalmol 1974;92:475-82.

5 Brodrick JD, Dark AJ, Geoffrey WP.

Fingerprint dystrophy of the cornea. Arch Ophthalmol 1974;92:483-9.

6 Ghanchi F, Ramsay A, Coupland S, et al. Ocular tumoral calcinosis. Arch Ophthalmol 1996;114:341-5.

\section{Fine retinal crystalline deposits observed by confocal scanning laser ophthalmoscopic} examination using infrared light

Bietti's crystalline retinopathy is a tapetoretinal degeneration characterised by numerous tiny sparkling yellow-white spots mainly located in the deeper layer of the posterior pole retina. ${ }^{1}$ Since crystalline deposits tend to become small and decrease in number over time, $^{23}$ the fundus appearance becomes indistinguishable from other retinal dystrophies with time. ${ }^{4}$ The advent of confocal scanning laser ophthalmoscope (SLO) with infrared light has enabled high sensitive examination of the deep layer of the retina. ${ }^{5}$ We studied the deep retinal abnormalities in a case with a typical Bietti's crystalline retinopathy and in another case with myopic chorioretinal atrophy throughout the posterior pole. Consequently, we detected numerous fine crystalline deposits in both cases, which were not detected with other funduscopic examinations.

\section{Case reports}

\section{Case 1}

A 52 year old man was referred to our hospital by his ophthalmologist who found an abnormal fundus appearance. There was no consanguinity. Best corrected visual acuity was 20/24 right eye and 20/50 left eye. No abnormalities were found in the anterior segment and media. Fine crystalline deposits were not detected in the corneal stroma of either eye. Funduscopic examination revealed numerous fine reflective crystalline deposits throughout the posterior pole and mid-peripheral retina of both eyes. Most of these deposits were in the deep retina and subretina but some deposits were superficial. Goldmann perimetry showed relative scotomas in a zone within 30-40 degrees of the central field in both eyes. Fluorescein angiography of both eyes showed island-like hypofluorescence lesions surrounded by hyperfluorescent lesions in the early phase. Indocyanine green angiography also showed the atrophy of the choriocapillaris in the posterior pole. Crystalline deposits did not show any fluorescence in either fluorescein or indocyanine green angiography.

The retinal crystalline deposits were more clearly visible with the fundus examination by SLO (Rodenstock, Germany) using infrared light compared to the routine funduscopic examinations (Fig 1). Each crystal deposit appeared larger in size. In addition, numerous fine crystal deposits were evident, which were not observed by conventional funduscopic examinations including ophthalmoscopy and 

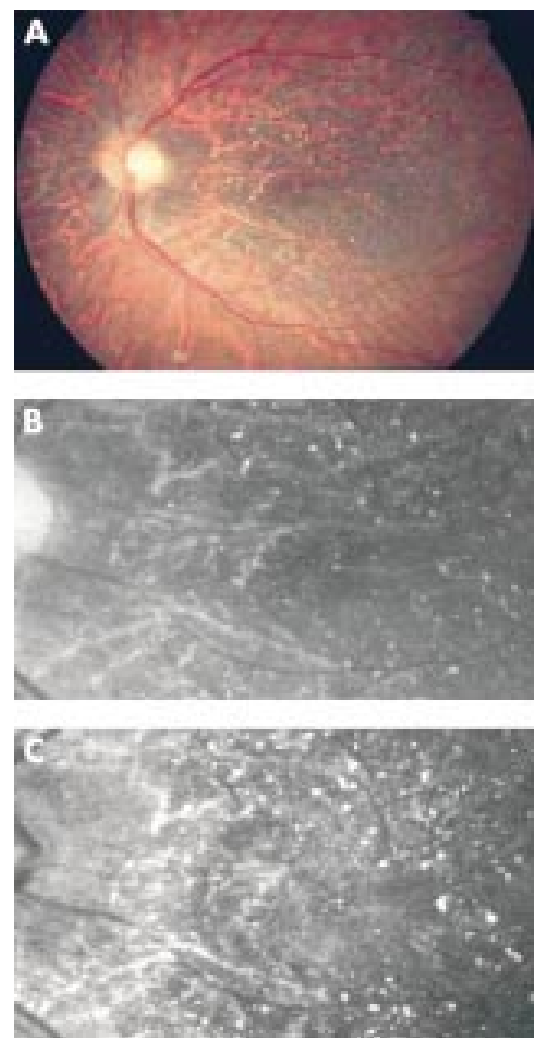

Figure 1 Ocular fundus of case 1. Fundus photograph (A), grey scale image of the same fundus photograph (B) and SLO image with infrared light (C) are shown. Note that the crystalline deposits are most evident with the infrared imaging.

slit lamp biomicroscopy using a contact lens. When the source of light was moved, the crystalline deposits scattered light and became more prominent.

\section{Case 2}

A 52 year old woman visited our hospital complaining of gradual visual loss in both eyes. She also noticed night blindness since childhood. Her parents were both high myopic and consanguineous. The extracapsular cataract extraction surgery was performed without complications in both eyes at the age of 43, and referring ophthalmologist reported that her fundus showed extensive chorioretinal atrophy in both eyes and that best corrected visual acuity was 20/1000 right eye and 20/1000 left eye after the cataract surgery. At initial visit to our hospital, best corrected visual acuity was right eye 20/200 and left eye 20/1000. Conjunctiva, cornea, anterior chamber, and vitreous were normal in both eyes
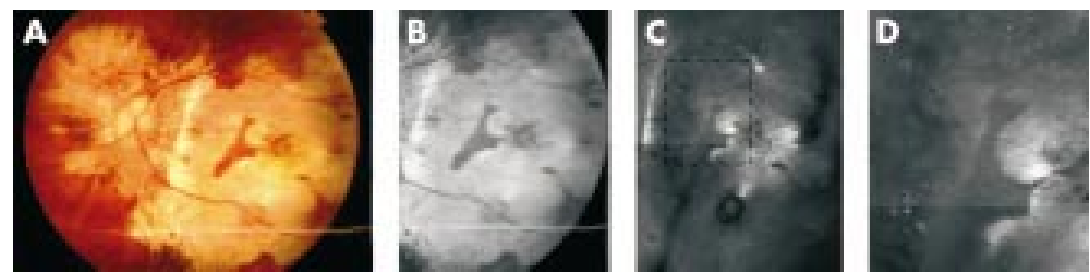

Figure 2 Ocular fundus of case 2. Fundus photograph (A), grey scale image of the same fundus photograph (B) and SLO image with infrared light (C). Magnified image of the boxed area is shown in (D). Note that numerous crystalline deposits are observed with the SLO imaging.

and no fine crystal deposits were found at limbs of either cornea. Both eyes were aphakic and the posterior lens capsules were intact but relatively opaque. Funduscopic examination revealed the posterior staphyloma and the extensive atrophy of the retinal pigment epithelium and choriocapillaris extending from the posterior to mid-peripheral retina in both eyes. Optic disc showed myopic appearance. Retinal vessels and peripheral retina showed normal appearance. Standard electroretinogram was non-recordable. Goldmann perimetry showed marked constriction of all isoptres and loss of visibility of I-4-e isoptre for both eyes. During a 5 year follow up, visual acuity and the fundus appearance were stationary. Fluorescein angiography performed at the age of 57 demonstrated hypofluorescence throughout the posterior pole in the early phase and diffuse hyperfluorescence in the later phase. Indocyanine green angiography disclosed the loss of background veil-like fluorescence throughout the posterior pole due to the choriocapillaris atrophy.

Fundus examination by the confocal SLO with infrared light disclosed numerous tiny crystalline deposits in the posterior pole (Fig 2 ), which were not evident with other funduscopic examinations, including ophthalmoscopy and biomicroscopy with a contact lens, or with fluorescein or indocyanine green angiographic studies. The deposits scattered light when the source of light was moved to cause them sparkle, similar to the fine crystalline deposits observed in the fundi of case 1 .

examinations did not show any abnormal value.

\section{Comment}

The diagnosis of Bietti's crystalline retinopathy in case 1 is based on the retinal crystalline and supported by the characteristic island-like hypofluorescence observed by fluorescein angiography. ${ }^{2}$ Fundus examination by SLO with the infrared light disclosed numerous tiny crystalline deposits, which were not observed by conventional fundus examinations. Thus, in Bietti's crystalline retinopathy, there are more numerous accumulation of retinal crystalline deposits than can be observed by funduscopic examinations.

In case 2, numerous tiny retinal crystalline deposits were detected by SLO with infrared light, although no other examinations disclosed these crystalline deposits. We have not observed such retinal crystalline deposits in other cases with myopic chorioretinal atrophy, suggesting the accumulation of crystalline deposits is not a generalised feature of myopic chorioretinal degeneration. Crystalline deposits, prerequisite for the diagnosis of Bietti's crystalline retinopathy, are difficult to detect in advanced cases. ${ }^{2-4}$ Since crystalline deposits do not block or transmit fluorescence in 

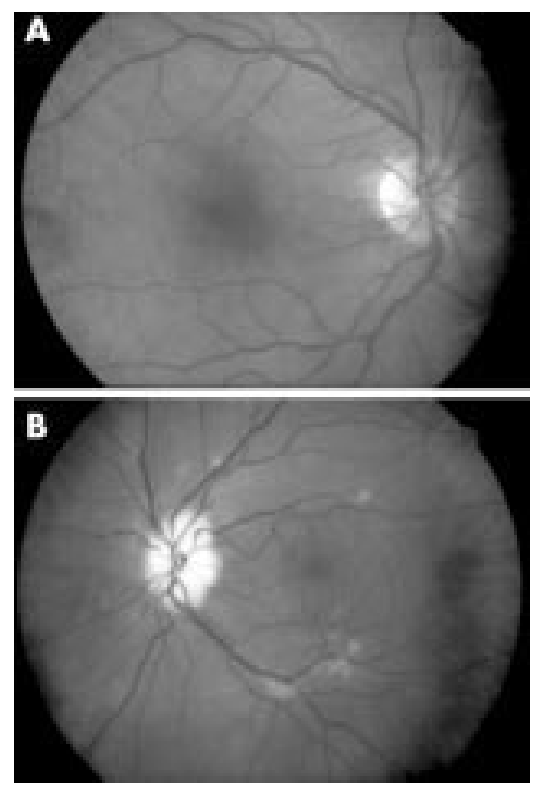

Figure 1 (A) The right optic disc and macula are normal. (B) The left optic disc is pale and swollen. Scattered cotton wool infarcts are seen within the macula.

neck discomfort and intermittent jaw claudication over the previous 2 weeks. She had no past medical or ocular problems.

Visual acuity was 20/20 in the right eye and no light perception in the left eye. The right pupil reacted briskly to light, with a normal consensual response, the left was amaurotic She identified all of the Ishihara pseudoisochromatic colour plates with the right eye and automated perimetry of the right eye was normal. Extraocular motility was normal. Funduscopy of the right eye (Fig 1A) was normal, and the left optic disc was pale and swollen, with retinal cotton wool infarcts within the retina, chiefly within the left macula (Fig 1B). The superficial temporal arteries were supple, pulsatile, and nontender. The Westergren erythrocyte sedimentation rate (ESR) was $114 \mathrm{~mm}$ in the first hour.

She was hospitalised and received intravenous methylprednisolone $250 \mathrm{mg}$ every 6 hours. Temporal artery biopsy was positive for GCA, including the presence of numerous giant cells. After 12 doses of methylprednisolone she was discharged on $80 \mathrm{mg}$ of oral prednisone per day.

Six days later her visual acuity remained $20 / 20$, and with a +2.00 dioptre add over a plano lens she read Jl print at 13 inches with the right eye. Automated perimetry and funduscopy of the right eye remained normal. However, the right pupil now reacted sluggishly to light (Fig 2A) while the left remained amaurotic. In addition, there was light near dissociation in both eyes, with bilateral tonic constriction to a near target followed by slow redilation. Slit lamp examination on the right revealed an irregular pupil (Fig 2B) with sectoral iridoplegia. Both pupils constricted following the instillation of topical $0.125 \%$ pilocarpine (Fig 2C).

She remained asymptomatic in her right eye and neuro-ophthalmic examination was unchanged 12 days later, except that her right pupil no longer reacted to direct light. Both pupils constricted slowly and tonically to a near target. Orbital colour Doppler imaging revealed no blood flow in the left central reti- nal artery (CRA), and blood flow in the right CRA was attenuated at $4.7 \mathrm{~cm} / \mathrm{s}$ (normal 10 $\mathrm{cm} / \mathrm{s}$ ). There was no flow detected in the short posterior ciliary arteries of the left eye, and attenuated flow in the short posterior ciliary arteries on the right. Although her ESR fell to $4 \mathrm{~mm}$ in the first hour and her jaw claudication resolved, the prednisone dose was maintained because of the attenuated blood flow within the right orbit. Her vision remained unchanged and her pupils remained nonreactive to light but with denervation supersensitivity, confirmed by constriction to $0.125 \%$ pilocarpine, 2 months after the onset of visual loss.

\section{Comment}

Five earlier reports have documented tonic pupils in patients with GCA. Davis and coworkers described a 69 year old woman who developed polymyalgia and anisocoria. ${ }^{2}$ The involved pupil constricted to $2.5 \%$ methacholine. In another report of tonic pupils from GCA mild supersensitivity to $0.1 \%$ pilocarpine was noted; however, the patient had counting fingers vision in each eye from bilateral optic neuropathy, suggesting that the light near dissociation may have been caused by bilateral afferent dysfunction. ${ }^{3}$ The authors cited pathological studies which have suggested ischaemia of the extraocular muscles as a cause of ophthalmoplegia in some patients with GCA,${ }^{4}$ and they implied that ischaemia was the cause of tonic pupils in their patient, although the site of damage was not specified. Currie and Lessell reported a 63 year old woman who had jaw claudication and loss of
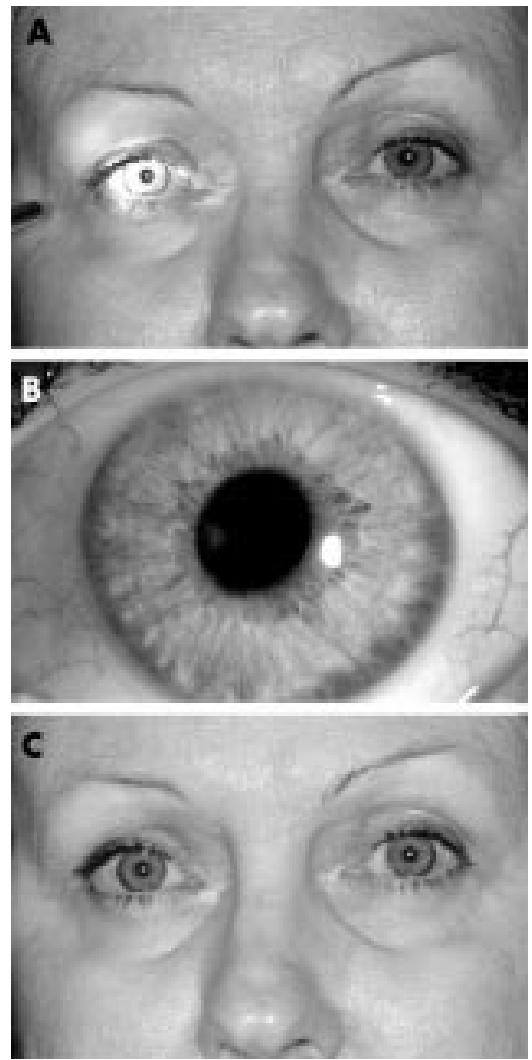

Figure 2 (A) The right pupil reacts sluggishly to light. (B) The right pupil is oval and the contour of the pupillary margin is asymmetric. (C) Both pupils constricted 30 minutes after instilling topical $0.125 \%$ pilocarpine. vision bilaterally from sequential anterior ischaemic optic neuropathy owing to biopsy proved GCA. ${ }^{5}$ After losing vision in each eye she developed bilateral tonic pupils which constricted markedly to $0.08 \%$ pilocarpine. These authors suggested that impaired orbital blood flow, including the blood supply to the ciliary ganglia or its postganglionic ciliary nerves, resulted in loss of axons and denervation supersensitivity, although no orbital blood flow studies were performed. They speculated that tonic pupils in patients with GCA may be overlooked because of the severity of visual loss.

Other authors have suggested that ischaemic damage may not be the sole cause of tonic pupils in patients with GCA. Bilateral tonic pupils with conjunctival injection were the only ocular manifestations in a 60 year old woman with biopsy proved GCA. ${ }^{6}$ Because there was no other clinical evidence of orbital or ocular ischaemia the authors postulated that damage to the ciliary ganglion may be mediated by an immunological mechanism. However, they did not quantitate the orbital or ocular blood flow, and our patient shows that clinical signs of ischaemia, except for tonic pupils, may be absent despite markedly decreased orbital blood flow.

Wilhelm reported five patients with bilateral visual loss from anterior ischaemic optic neuropathy or central retinal artery occlusion and tonic pupils from GCA. ${ }^{7}$ Assessment of orbital blood flow was performed using ultrasonography in three of these patients. In two patients no flow was noted in the supratrochlear arteries, while blood flow in the third was normal. The author noted that the ultrasonographic results supported ischaemia as a cause for the tonic pupils. In the patient with normal orbital blood flow, ischaemia below the resolution of ultrasonography was presumed to cause the tonic pupils.

The blood supply to the ciliary ganglion arises from several sources. Eliskova studied 18 human cadaveric orbits after injection of dye into the internal carotid artery. ${ }^{8}$ The ciliary ganglion was supplied with blood from one to four arteries, with the posterior lateral ciliary artery and the lateral muscular artery the most common sources, followed by the ophthalmic and central retinal artery. The vasculature of the ganglion itself is composed of a network of capillaries.

Orbital colour Doppler imaging is a noninvasive way to quantitate blood flow to the orbit and eye. Decreased blood flow in the ophthalmic artery, central retinal artery, and short posterior ciliary arteries may be detected on orbital colour Doppler imaging in patients with GCA. ${ }^{9}$ Markedly reduced blood flow was found with orbital colour Doppler imaging in both orbits in our patient, despite her visual loss being unilateral. We were unable to find a previous report of bilateral tonic pupils in a patient with unilateral visual loss from GCA. Although anterior segment ischaemia can cause loss of iris sphincter tone, we do not believe that the pupillary findings in our patient resulted from iris ischaemia. Iris ischaemia would result in poorly reactive pupils to both light and accommodation, without a tonic near reaction or denervation hypersensitivity. Therefore, the findings in our patient strongly suggest that the tonic pupils resulted from ischaemic damage to the ciliary ganglion or the postganglionic ciliary nerves which are responsible for pupillary constriction.

The authors do not have any proprietary interests in any of the contents of this manuscript.

Dr Foroozan is supported by the Heed Ophthalmic Foundation, Cleveland, OH, USA. 
R Foroozan, L M Buono, P J Savino, R C Sergott Neuro-Ophthalmology Service, Wills Eye Hospital, Thomas Jefferson University, 900 Walnut Street Philadelphia, PA 19107, USA

Correspondence to: P J Savino; pisavino@aol.com Accepted for publication 12 September 2002

\section{References}

1 Bourgon P, Pilley FJ, Thompson HS. Cholinergic supersensitivity of the iris sphincter in Adie's tonic pupil. Am J Ophthalmol 1978;85:373-7

2 Davis RH, Daroff RB, Hoyt WF. Tonic pupi after temporal arteritis. Lancet 1968; 1:822.

3 Bronster DJ, Rudolph SH, Shanzer S. Pupillary light-near dissociation in cranial arteritis. Neuro-Ophthalmology 1982;3:65-70.

4 Barricks ME, Traviesa DB, Glaser JS, et al. Ophthalmoplegia in cranial arteritis. Brain 1977; 100:209-21.

5 Currie J, Lessell S. Tonic pupil with giant cell arteritis. Br J Ophthalmol 1984;68:135-8.

6 Coppeto JR, Greco T. Mydriasis in giant-cell arteritis. J Clin Neuro-ophthalmol 1989:9:267-9.

7 Wilhelm H. Pupillotonie durch ischamie [Tonic pupil caused by ischemia]. Fortschr Ophthalmol 1989:86:380-2.

8 Eliskova $M$. Blood vessels of the ciliary ganglion in man. Br J Ophthalmol 1973;57:766-72.

9 Aburn NS, Sergott RC. Orbital colour Doppler imaging. Eye 1993;7:639-47.

\section{Frozen cucumber as a mount for processing vitreoretinal specimens}

Vitreoretinal specimens are extremely difficult to process as a frozen specimen because of their small size and tendency to roll up. ${ }^{1}$ How ever, in order to perform immunohistochemical tests it is sometimes necessary to have frozen specimens as antigens may be destroyed if a fixative agent is used.

Dua et $a l^{2}$ and Scott et $a l^{3}$ suggested the use of frozen cucumber as a mount for conjunctival and corneal tissue; we modified this method for vitreoretinal specimens. We describe our technique and provide examples of our results.

\section{Case report}

Fresh cucumber (obtained from a greengrocer) was cut into small $\left(\mathrm{l} \mathrm{cm}^{3}\right)$ blocks; the part devoid of seeds was used. We found that with cucumbers older than 2 days the membranes did not adhere sufficiently well. These blocks were then stored at $4^{\circ} \mathrm{C}$ until required. Pig eyes were obtained and stored at $4^{\circ} \mathrm{C}$ until required. Subsequently, the eye was placed under the dissecting microscope and basic salt solution injected in through the vitreous cavity to enable easier dissection. The cornea was

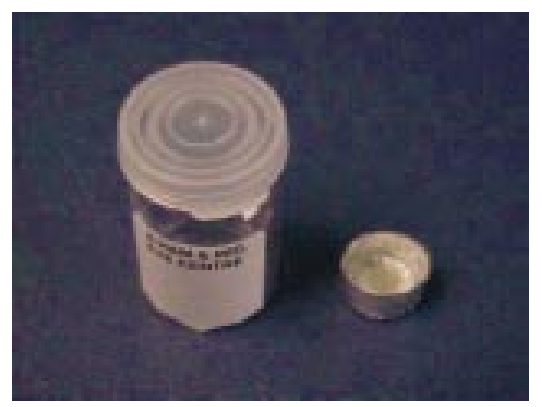

Figure 1 The biopsy cucumber unit.

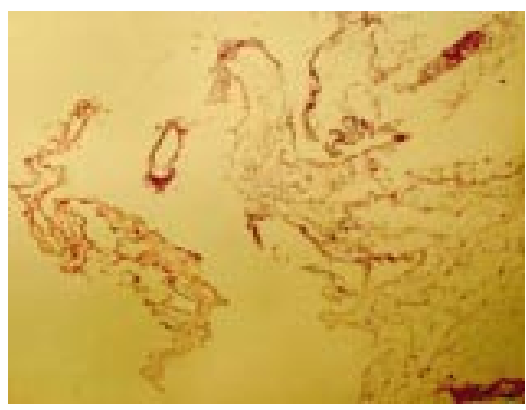

Figure 2 Diabetic membrane on cucumber mount stained with haematoxylin and eosin.

removed and a vitrectomy performed. The retinal specimens were stained with Indian ink in order to facilitate subsequent localisation.

Following vitrectomy, membranes were removed from humans (these included diabetic membranes, subretinal neovascular membranes, and epiretinal membranes); they were initially placed in Hartmann's solution. Subsequently, they were placed on the cucumber under a dissecting microscope; it was possible to place the membrane flat without it rolling up because of the texture of the cucumber. These membranes were also stained with Indian ink before placing on the cucumber.

The cucumber with the membrane on its "side" surface was placed in an aluminium foil cup and covered with a cryomatrix of Tissue-Tek OCT compound (Fig 1). The foil cup was then put in a plastic container and the contents flash frozen in liquid nitrogen.

The membranes were cut with a cryostat in 4-5 $\mu \mathrm{m}$ sections. We stained one slide from each specimen with haematoxylin and eosin and performed immunohistochemistry on the others (Figs 2 and 3).

No specimens were lost while performing this technique of processing specimens.

We were able to maintain the orientation of the specimens and managed to obtain sufficiently satisfactory specimens to perform our immunohistochemical studies. The use of Indian ink allowed us to locate the specimen easily when cutting sections. Unlike previous studies we found that the specimen attached to the cucumber without the use of albumin.

\section{Comment}

Swan and Davis first described the biopsy cucumber unit for processing cervical specimens. ${ }^{4}$ Frozen cucumber has been described as a mount for bladder and lung biopsies. $^{5}$

Ocular tissues that have been processed in this fashion are conjunctiva and cornea. Whittle et al described a technique using

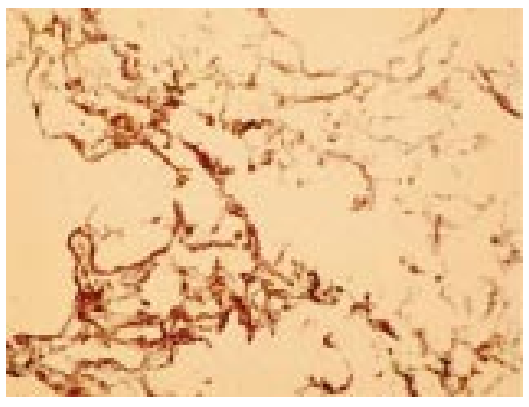

Figure 3 Diabetic membrane on cucumber mount stained with CD31. cucumber as a mount for processing cadaveric human retina, ${ }^{8}$ which enabled indirect immunofluorescence studies.

Retinal specimens are difficult to process because of their size, tendency to roll up and, hence, difficult orientation. Nevertheless, it is necessary to process specimens in this way to perform certain immunohistochemistry techniques.

We suggest that cucumber is a suitable mount for vitreoretinal membranes that are required as frozen specimens for immunohistochemistry. It should be noted that most modern immunohistochemistry may be performed on fixed tissue.

Presented at British Association of Ophthalmic Pathologists Annual Meeting, Dunchurch, March 2002

Each author states that he has no proprietary interest in the development or marketing of any product used in this study.

S Banerjee, C Shaikh, G R Wallace,

P I Murray

Academic Unit of Ophthalmology, University of Birmingham, Birmingham, UK

R A H Scott

Vitreoretinal Unit, City Hospital NHS Trust, Birmingham, UK

Correspondence to: Professor P I Murray, Academic Unit of Ophthalmology, Division of Immunity and Infection, Birmingham and Midland Eye Centre, Sandwell and West Birmingham Hospitals NHS Trust, City Hospital, Dudley Road, Birmingam B18 7QU, UK; P.I.Murray@bham.ac.uk

Accepted for publication 13 September 2002

\section{References}

1 Hiscott P, Wong D, Grierson I. Challenges in ophthalmic pathology: the vitreoretinal membrane biopsy. Eye 2000;14,549-59.

2 Dua HS, Gomes JAP, Singh A, et al. Fresh-frozen cucumber as a mount for conjunctival and corneal tissue in cryomcirotomy. Arch Ophthalmol 1994:112:1139-40.

3 Scott RA, Lauweryns B, Snead DM, et al. E-cadherin distribution and epithelial basement membrane characteristics of the normal human conjunctiva and cornea. Eye 1997:11 ( Pt 5):607-12.

4 Swan RW, Davis HJ. The biopsy-cucumber unit. A method to improve tissue orientation. Obstet Gynecol 1970;36:803-5.

5 Watson RA, Fitzwater JE, Deshon GE Jr, et al. Biopsy-cucumber unit: improved method for preparing bladder biopsy specimens. Urology 1984;23:392-3.

6 Brodersen BW, Kelling CL. A cucumber mount for processing lung biopsy specimens from calves. J Vet Diagn Invest

1996:8:518-9.

7 Erie JC, Collyer SK, Campbell RJ. Dehydrated cucumber slice as a mount for conjunctival biopsy specimens. Am J Ophthalmol 1985:99:539-41.

8 Whittle RM, Wallace GR, Whiston RA, et al. Human antiretinal antibodies in toxoplasma retinochoroididtis. $\mathrm{Br} J$ Ophthalmol 1998;82:1017-21.

\section{Inflammatory optic neuropathy as the presenting feature of herpes simplex acute retinal necrosis}

Acute retinal necrosis (ARN) is a rare but serious ophthalmic manifestation of infection by the herpesvirus family. In the immunocompetent, the viral agent most frequently identified is varicella zoster (VZV) followed by herpes simplex (HSV-1 and HSV-2) and rarely 

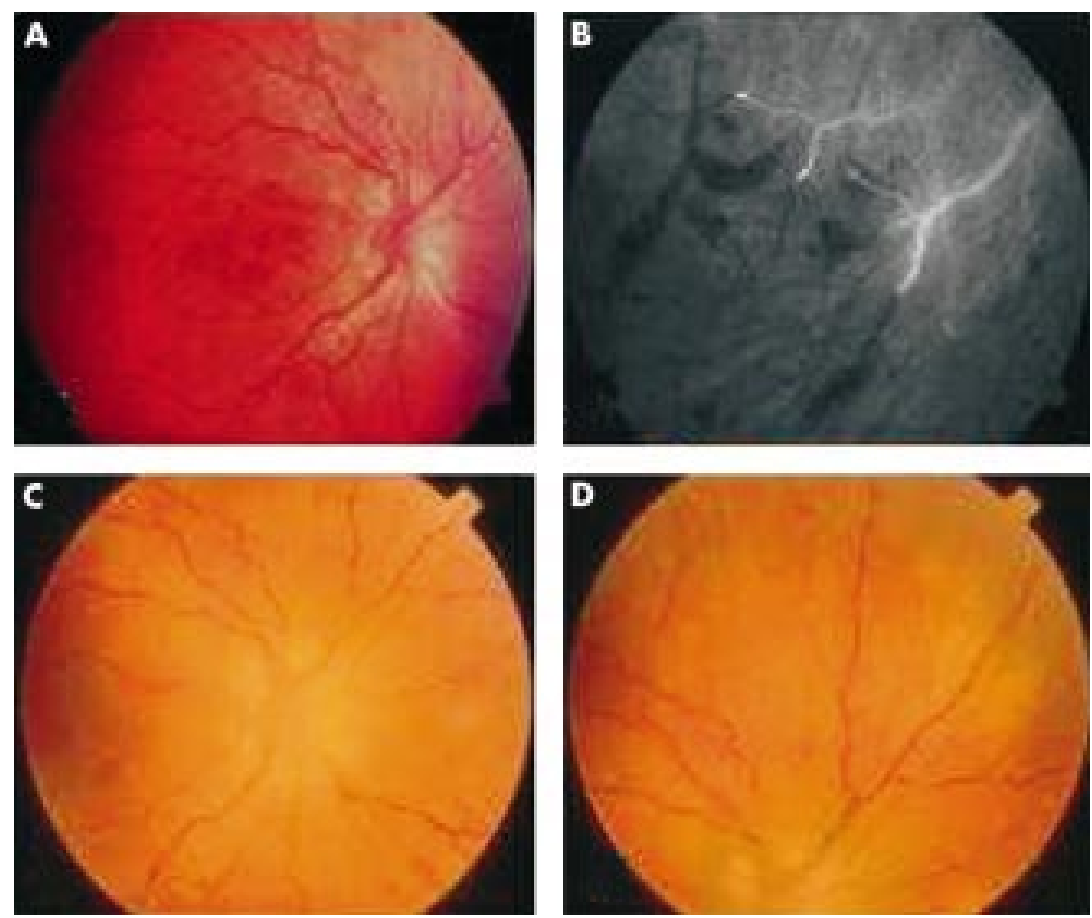

Figure 1 (A) Colour photograph of right posterior pole (case 1, 20 year old man) showing marked swelling of the right optic disc and several retinal haemorrhages; (B) fundus fluorescein angiography of same eye mid-venous phase showing peripheral retinal occlusive arteritis and ischaemia; (C) and (D), persistent disc swelling and patches of acute retinal necrosis.

cytomegalovirus and Epstein-Barr virus. The condition, which may present with synchronous or metachronous systemic or cerebra herpetic infection (encephalitis) is now recognised to occur at all ages, ${ }^{1}$ though VZV tend to affect the more elderly and herpes simplex the young.

The majority of patients present with a short history of blurred vision, floaters, and mild ocular discomfort. In the immunocompetent, clinical examination reveals one or more well demarcated foci of retinal necrosis outside the major arterial arcades typically with a dense vitritis that may preclude detailed view of the posterior segment. Disease progression is rapid with coalescence and posterior extension of areas of retinitis Often there is an occlusive, sometimes haem orrhagic, vasculitis either adjacent to areas of retinitis or at the optic nerve. The visual prognosis for untreated cases is very poor. ${ }^{2}$

We report three immunocompetent patients with no evidence of concurrent herpesvirus infection in whom ipsilateral optic neuritis associated with a panuveitis was the presenting feature of their acute retinal necrosis syndrome.

\section{Case reports}

\section{Case 1}

A 20 year old healthy white male, with no his tory of herpesvirus infection, presented with a 10 day history of progressive blurred right vision with floaters, significant periocular discomfort, and pain on ocular motility. Acuity was 20/200 right eye, 20/20 left eye, with a right relative afferent pupillary defect (RAPD). There was swelling of the right optic nerve (Fig lA) together with increasing nongranulomatous pan uveitis. The left eye was unaffected. Fluorescein angiography (Fig lB) showed marked optic disc hyperfluorescence and peripheral retinal ischaemia. Seven days later (Fig $\mathrm{IC}$ and D), several enlarging foci of retinitis, typical of $A R N$, developed in the retinal mid-periphery. PCR of a vitreous biopsy amplified HSV-1. There was no further reduction in visual acuity following intravitrea foscarnet and encephalitic doses $(10 \mathrm{mg} / \mathrm{kg}$ three times daily) of intravenous aciclovir for 10 days.

\section{Case 2}

A 47 year old healthy white female, with no history of prior herpesvirus infection, presented with a 3 day history of progressive blurred left vision. She also complained of significant periocular discomfort exacerbated by eye movement. Acuity was 20/40 left eye, 20/15 right eye, with a left RAPD. There was swelling of the left optic nerve head together with a moderate non-granulomatous panuveitis. The right eye was unaffected. Fluorescein angiography showed marked optic disc hyperfluorescence and peripheral retinal ischaemia. Six days later, several enlarging foci of retinitis, typical of ARN, developed in the inferior retinal periphery. Polymerase chain reaction (PCR) of a vitreous biopsy amplified HSV-1. There was no further reduction in visual acuity following encephalitic doses ( 10 $\mathrm{mg} / \mathrm{kg}$ three times daily) of intravenous aciclovir for 10 days.

\section{Case 3}

An 81 year old white male, who had suffered herpes simplex meningoencephalitis and synchronous right acute retinal necrosis (acuity reduced to 20/200) 17 years earlier, presented with a 2 day history of profound reduction in left acuity to perception of light only. Clinical findings included a left RAPD, haemorrhagic optic disc swelling, and increasing hypertensive panuveitis. Five days later, three demarcated areas of retinal necrosis appeared superiorly in the same eye. PCR of a vitreous biopsy amplified HSV-1. There was no further reduction in visual acuity following intravitreal foscarnet and 10 days of encephalitic doses ( $10 \mathrm{mg} / \mathrm{kg}$ three times daily) of intravenous aciclovir.

\section{Comment}

There have been two previous reports in immunocompromised patients of optic neuritis preceding the development of ARN. ${ }^{34}$ In these, preceding or concurrent cutaneous herpes zoster infection suggested altered viral behaviour in the context of deficient immunity. Even in the healthy individual, there is evidence of an immunogenetic predisposition to the development of the disease. ${ }^{5}$ The novel mode of presentation of our three immunocompetent patients suggests they might share a similar background of immunity that modifies viral behaviour, thereby predisposing to involvement of the optic nerve before the development of retinitis. In this regard, it is interesting that none of our cases developed clinically evident encephalitis. This is a common accompaniment to human HSV-l ARN and observed in the Szily animal model in which inoculation of the anterior chamber or vitreous with HSV virus produces in ipsilateral anterior uveitis, relative sparing of the ipsilateral retina, and necrotising contralateral chorioretinitis with encephalitis. It has been shown that viral spread to the brain and the fellow eye results from viral invasion of the optic nerve. ${ }^{6}$ The ability of the host to resist this appears determined by the animal's immune background.

The recent report in a single case of ARN subsequent to central retinal vascular obstruction in the fellow eye is most likely a manifestation of a different VZV mediated disease process ${ }^{8}$ but emphasises the ability of members of the herpesvirus family to directly invade blood vessel walls.

The combination of optic neuritis, peripheral retinal ischaemia, and panuveitis is very unusual. In white patients, the differential diagnosis would include conditions such as sarcoidosis and demyelinating disease for which steroid therapy is often routine and may prove beneficial. This report highlights that herpesvirus infections may also present in this fashion. Since progression to profound and irreversible visual loss is rapid, close daily retinal examination, and early diagnostic vitreous biopsy must be recommended for these patients before commencement of immunosuppressives.

P J Francis, H Jackson, M R Stanford, E M Graham

St Thomas's Hospital, London, UK

Correspondence to: Peter Francis, St Thomas's Hospital, London, UK peterjamesfrancis@btopenworld.com

Accepted for publication 3 October 2002

\section{References}

1 Tan J, Byles D, Stanford M, et al. Acute retinal necrosis in children caused by herpes simplex virus. Retina 2001;21:344-7.

2 Walters G, James T. Viral causes of the acute retinal necrosis syndrome. Curr Opin Ophthalmol 2001;12:191-5.

3 Friedlander S, Rahhal F, Ericson L, et al. Optic neuropathy preceding acute retina necrosis in acquired immunodeficiency syndrome. Arch Ophthalmol 1996;114:1481-5

4 Meenken C, Horn Gvd, Smet Md, et al. Optic neuritis heralding varicella zoster virus retinitis in a patient with acquired immunodeficiency syndrome. Ann Neurol 1998;43:534-6. 
5 Holland G, Cornell P, Park M, et al. An association between acute retinal necrosis syndrome and HLA-DQw7 and phenotype Bw62, DR4. Am J Ophthalmol

1989;108:370-4.

6 Olson R, Holland G, Goss S, et al. Routes of viral spread in the von Szily model of herpes simplex virus retinopathy. Curr Eye Res 1987;6:59-62.

7 Zaltas M, Opremcak E, Hemady R, et al. Immunohistopathologic findings in herpes simplex virus chorioretinitis in the von Szily model. Invest Ophthalmol Vis Sci 1992; 33:68-77

8 Kang S, Kim S. Optic neuropathy and central retinal vascular obstruction as initial manifestations of acute retinal necrosis. Jpn J Ophthalmol 2001;45:425-8.

\section{Cutaneous angiosarcoma of the eyelids}

Angiosarcoma of the eyelid is a rare potentially life threatening tumour arising from the vascular endothelium. Through the presentation of a case, the clinicopathological features and management of this condition are described.

\section{Case report}

A 69 year old white man presented with multifocal red-blue maculopapular lesions located in his right cheek and eyelids (Fig lA). The patient had first noticed the lesions 9 months previously. An incisional biopsy from the upper eyelid was performed. In subsequent staging investigations no metastases were found. The patient was otherwise in good health and was HIV negative. He underwent surgical resection of all clinically detectable lesions followed by adjuvant radiotherapy (total dose $45 \mathrm{~Gy}$ ). After 34 months of follow up there was no evidence of local recurrence or distant metastases.

Histopathologically, the specimens consisted of skin and subcutaneous tissue. The lesions proved to be well differentiated angiosarcoma characterised by interlacing blood vessels lined by plump endothelial cells with hyperchromatic nuclei. Using Ki-67, the proliferation rate was assessed as 5\%-7\% (Fig 1B). Immunohistochemically, the tumour cells showed a positive reaction for vimentin CD34 (human haemopoietic progenitor cell antigen) and FVIII-RA. They were consistently negative for S100 and HMB45 (results not shown).

\section{Comment}

Cutaneous angiosarcoma is a distinct subgroup of angiosarcomas most commonly seen in the skin and superficial soft tissues in patients over 55 years. ${ }^{1}$ The majority of these tumours arise in the head and neck area, particularly the scalp. They are aggressive and tend to recur locally and disseminate widely with a 5 year survival of approximately $12 \%-$ $29 \% .^{12}$ To our knowledge, there are only seven well documented cases involving the eyelid. ${ }^{3-8}$ Clinically, the lesions in our patient resembled those previously reported in view of the purple coloured maculopapular lesions, suggesting a vascular origin. ${ }^{13-8}$ In $50 \%$ of cases the lesions are multifocal. ${ }^{1}$ Often the lesions are poorly defined and the true extent of disease may be difficult to determine clinically. ${ }^{12578}$ The differential diagnosis includes ecchymoses, capillary haemangioma, melanoma, and Kaposi's sarcoma. Advanced lesions may ulcerate and atypical cases simulating, cellulitis, rosacea and xanthelasma have also been reported. ${ }^{35-8}$ Owing to lack of clinical awareness and the varied presentation, diagnosis is often delayed.'
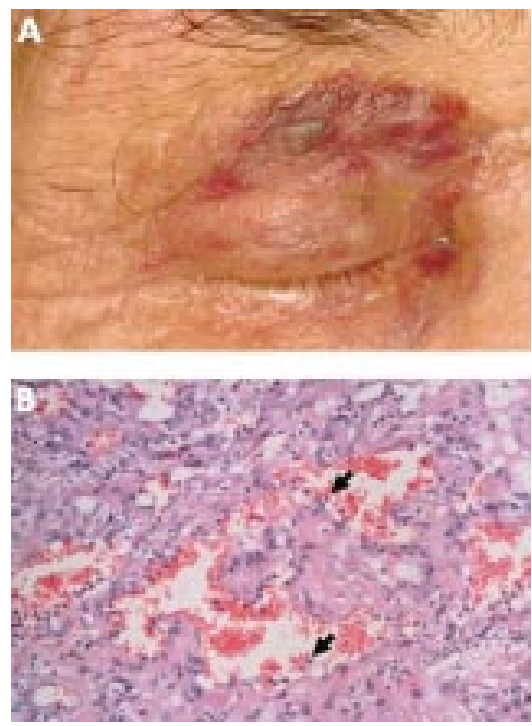

Figure 1 (A) Magnified view of lid lesions. (B) Light micrograph showing well differentiated angiosarcoma characterised by distinct blood vessel formation. In areas, malignant endothelial cells pile up producing typical papillary projections into the lumina (short arrow) (PAS $\times 200$ ).

Histologically, angiosarcomas display a spectrum from well to poorly differentiated varieties. The present case was consistent with a well differentiated angiosarcoma with characteristic interlacing channels lined by atypical endothelial cells and expression of immunohistochemical markers of vascular differentiation (CD34 and FVIII-RA). ${ }^{9}$ Often tumours display both vasoformative and undifferentiated areas. ${ }^{9}$ The present case was noteworthy, in that the entire tumour appeared to be well differentiated. The proliferation rate was low to moderate compared to the reported rate for angiosarcoma (>10\% in $72 \%$ of cases assessed by Ki-67). ${ }^{10}$ Mitotic index has been observed as an independent histological prognostic marker for cutaneous angiosarcoma although other histological makers remain poorly defined. ${ }^{11}$ In the present case low proliferation index and well differentiated histological features may have contributed to a better outcome.

The most important clinical prognostic factor is lesion size, with tumours $<5 \mathrm{~cm}$ in diameter having a better prognosis. ${ }^{11}$ This underlies the importance of early diagnosis and appropriate management. The mainstay of treatment for cutaneous angiosarcoma includes surgery and/or radiotherapy although, due to the rarity of this condition, there are no standard guidelines. ${ }^{2}{ }^{12}$ As illustrated by our case, the primary lesions were contained within the anterior lamella of the lids and it was possible to surgically encompass the primary lesions avoiding exenteration and without compromising prognosis. In such cases, the surgical aim is to resect all clinically identifiable disease. In areas of doubt, microscopic control of surgical margins may have a role in guiding the extent of resection. Angiosarcomas usually respond to radiotherapy to some degree and most authors suggest that combined surgery and radiotherapy offers the best chance for long term control. ${ }^{2}$ In one series of 28 head and neck angiosarcomas, Mark et $a l^{12}$ have reported better survival after 32 months (median) with combined surgery and radio- therapy compared with surgery alone. In cases unsuited to surgery, radiotherapy alone may be considered, however usually only partial responses are achieved. ${ }^{2}{ }^{12}$ The role of chemotherapy remains undefined.

In summary, cutaneous angiosarcoma should be included in the differential diagnosis of vascular or atypical eyelid lesions as early recognition is critical to optimise outcome. Classification of the mitotic index and degree of histopathological differentiation may be useful criteria in predicting the biological behaviour. Treatment needs to be individualised to the patient and in selected cases complete excision of clinically evident disease may be appropriate. Adjuvant radiotherapy is recommended due to the aggressive natural history of angiosarcoma.

\section{Acknowledgements}

The excellent technical assistance of Carmen Hofmann-Rummelt is acknowleged. The study was supported in part by the Alexander von Humboldt Foundation, Bonn, Germany (RMC), The Deutsche Forschungsgemeinschaft, Bonn, Germany (TH), Allergan Australia in conjunction with The Royal Australian and New Zealand College of Ophthalmologists and Sydney Eye Hospital (RMC).

R M Conway, T Hammer, A Viestenz,

L M Holbach

Department of Ophthalmology and Eye Hospital, University of Erlangen-Nürnberg, Erlangen,

R M Conway

Alexander von Humboldt Fellow and Lecturer Save Sight Institute, University of Sydney, Australia

Corresondence to: R Max. Conway, MD, PhD Department of Ophthalmology and Eye Hospital, University Erlangen-Nürnberg, Schwabachanlage 6, D-91054 Erlangen, Germany; rmaxconway@hotmail.com

Accepted for publication 8 October 2002

\section{References}

1 Holden CA, Spittle MF, Wilson Jones E. Angiosarcoma of the face and scalp, prognosis and treatment. Cancer 1987, 59:1046-57.

2 Morrison WH, Byers RM, Garden AS, et al. Cutaneous angiosarcoma of the head and neck. A therapeutic dilemma. Cancer 1995;76:319-27.

3 Panizzon R, Schneider BV, Schnyder UW Rosacea-like angiosarcoma of the face. Dermatologica 1990;181:252-4.

4 Bray LC, Sullivan TJ, Whitehead K. Angiosarcoma of the eyelid. Aust NZ J Ophthalmol 1995;23:69-72.

5 Gündüz K, Shields JA, Shields CL, et al. Cutaneous angiosarcoma with eyelid involvement. Am J Ophthalmol 1998; 125:870-1.

6 Lapidus CS, Sutula FC, Stadecker M, et al. Angiosarcoma of the eyelid: yellow plaques causing ptosis. J Am Acad Dermatol 1996;34:308-10.

7 Mehrens C, Anvari L, Grenzebach UH, et al Unilateral eyelid swelling as an initial manifestation of angiosarcoma. Der Hautarzt 2000;51:419-22.

8 Tay YK, Ong BH. Cutaneous angiosarcoma presenting as recurrent angio-oedema of the face. Br J Derm 2000;143:1346-8.

9 Oshawa M, Naka N, Tomita Y, et al. Use of immunohistochemical procedures in diagnosing angiosarcoma. Evaluation of 98 cases. Cancer 1995;75:2867-74.

10 Meis-Kindblom JM, Kindblom LG Angiosarcoma of soft tissue: a study of 80 cases. Am J Surg Pathol 1998;22:683-97.

11 Naka N, Ohsawa M, Tomita Y, et al. Prognostic factors in angiosarcoma: a multivariate analysis of 55 cases. J Surg Oncol 1996;61:170-6. 
12 Mark RJ, Tran LM, Sercarz J, et al Angiosarcoma of the head and neck. The UCLA experience 1955 through 1990. Arch Otolaryngol Head and Neck Surg 1993;119:973.

\section{Permanent visual loss in a child with a rash}

Endophthalmitis is an unusual but well described complication of bacteraemia. Here we report endophthalmitis arising in the course of a mild illness resembling chickenpox.

\section{Case report}

A previously healthy 6 year old white girl awoke in the early hours feeling hot and complaining of headache. She was given ibuprofen and she went back to sleep. Spots appeared on her limbs later the same day but they blanched beneath a glass bottle and several developed into small blisters. A classmate was known to have chickenpox. Next day some new spots appeared on her buttocks, and some of the older lesions appeared to be crusting over. She was noticed rubbing her right eye and later said she felt warm, and vomited. Next morning she complained of pain in the right eye and could not open it Following assessment by her general practitioner she was referred urgently to an eye unit.

On examination she appeared well and was afebrile. The right eye was chemotic, with an absent red reflex and a large hypopyon (Fig 1). Erythematous maculopapular lesions were present on her arms, legs, and face.

Investigations included a white cell coun of $8.0 \times 10^{9} / 1$ (neutrophils $4.0 \times 10^{9} /$ ) and $C$ reactive protein $22 \mathrm{mg} / \mathrm{l}$. Material was collected from the base of the sole remaining vesicle, on her shin. Ciprofloxacin was commenced parenterally at a dose of $100 \mathrm{mg}$ twice daily $(10 \mathrm{mg} / \mathrm{kg} /$ day $)$. Examination under general anaesthesia revealed a panophthalmitis with total corneal abscess and hypopyon. There was no evidence of a puncture wound to suggest exogenous infection. Aqueous humour was aspirated, and intravitreous amikacin and vancomycin administered. Vitrec tomy could not be performed because of the severe anterior segment inflammation.

Electron microscopy, immunofluorescence staining and polymerase chain reaction (PCR) testing of the vesicular material was negative for varicella zoster virus (VZV) and herpes simplex virus. Neither IgM nor IgG against

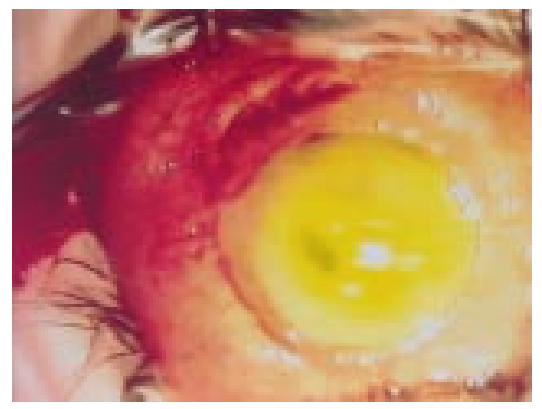

Figure 1 Right eye showing panophthalmitis. There is a diffuse corneal infiltrate and a purulent exudate in the anterior chamber leading to the opaque appearance of the cornea and the absence of any view of the iris or pupil. The sclera is exposed in the upper temporal quadrant and is infiltrated and thinned.
VZV was detected in the blood. Cultures of blood and aqueous humour were negative but urgent Gram stain of the aqueous humour revealed scanty intracellular Gram negative diplococci. Meningococcus C DNA was detected in the aqueous and in the skin scraping, but not in blood, by PCR testing.

The patient was apyrexial and remained clinically well during her hospital admission. At discharge after 5 further days of parenteral antibiotics (ceftriaxone) the rash had completely resolved. In the absence of a positive culture sensitivities could not be confirmed, although all the stated antibiotics except vancomycin are generally effective against meningococcus. At follow up the eye had become phthisical, with visual acuity reduced to perception of light only.

\section{Comment}

In this case meningococcal endophthalmitis, usually seen in association with clinically apparent septicaemia and meningitis, ${ }^{1}$ occurred in the setting of a mild illness thought to be chickenpox. Although the usual hallmarks of meninogococcal sepsis were absent, evidence for seeding of the eye in the course of a transient meningococcaemia was provided by Gram negative intracellular diplococci in the aqueous humour and detection of meningococcal DNA in both the aqueous humour and cutaneous material. Reports of meningococcal endophthalmitis in clinically well, nonbacteraemic patients are very rare, with just four published cases in English. The patients were 13 months, ${ }^{2} 15$ years, ${ }^{3} 17$ years, ${ }^{4}$ and 23 years ${ }^{5}$ old. Both eldest and youngest had no skin lesions, but were pyrexial at presentation. The 15 year old had a low grade fever and a generalised macular rash misdiagnosed as scarlet fever. The 17 year old appeared completely "non-septic" with a 4 day history of myalgia, arthralgia, sore throat, and transient fever. A vesicular rash on the lower extremities appeared vasculitic on histological examination. In all of these cases only one eye was involved. Meningococcus type $\mathrm{C}$ was isolated from the eye in two cases, type B in a third, and in the fourth case the type was not stated. The outcome was bad in each case. In the three older patients vision was reduced to the perception of light only, with dense cataracts forming in two, and pthisis in the 23 year old who underwent vitrectomy. The 13 month old underwent vitrectomy and lensectomy, and the plan at publication was to provide the patient with a new lens.

Vesicles are not generally regarded as lying within the spectrum of rashes caused by meningococcal infection. The acute ocular complications of varicella infection include spread of vesicles to the eyelid, papillary conjunctivitis and, uncommonly, dendritic keratitis, acute retinal necrosis, and optic neuritis. Hypopyon, observed in this case, is not a feature of primary VZV infection.

This report serves to emphasise the broad clinical spectrum of meningococcal disease, and highlights the potential for severe sequelae despite an otherwise effective host response to bacteraemia. Seeding of group C meningococci resulted in visual loss in this young patient for whom the UK conjugate vaccine programme came just a year too late.

P A Berry, J K Dart, E Graham, $M$ Matheson, E M E MacMahon St Thomas's Hospital, London UK
Correspondence to: Philip Berry, St Thomas's Hospital, London UK; philaberry@hotmail.com

Accepted for publication 10 October 2002

\section{References}

1 Steven N, Wood M. The clinical spectrum of meningococcal disease. In: Cartwright K, ed. Meningococcal disease. Chichester: John Wiley, 1995: 177-205

2 Auerbach SB, Leach CT, Bateman BJ, et al. Meningococcal endophthalmitis without concomitant septicaemia or meningitis. Paed Inf Dis J 1989;8:41 1-13.

3 Brisner JH, Hess JB. Meningococcal endophthalmitis without meningitis. Can $J$ Opthalmol 1981;16:100-1.

4 Sleep T, Graham M. Meningoccal endophthalmitis in a well patient [letter]. $J$ Opthalmol 1997; 81:1016-20.

5 Kearns AM, Sprott MS. Endophthalmitis caused by Neisseria meningitidis. J Infect 1991;22:299-300.

6 Ritterband DC, Friedberg DN. Virus infection of the eye. Rev Med Virol 1998;8:187-201.

\section{MAILBOX}

If you have a burning desire to respond to a paper published in the BJO, why not make use of our "rapid response" option?

Log on to our website (www.bjophthalmol.com), find the paper that interests you, and send your response via email by clicking on the "eletters" option in the box at the top right hand corner

Providing it isn't libellous or obscene, it will be posted within seven days. You can retrieve it by clicking on "read eletters" on our homepage.

The editors will decide as before whether to also publish it in a future paper issue.

\section{Those excrescences on \\ Descemet's membrane}

We read with interest the recent report, "Screening human donor corneas during organ culture for the presence of guttae."1 Even the title made us question whether we were the only ones still using the original name for the condition cornea guttata. A quick perusal of Medline reveals a trend away from guttata, and towards guttae (Fig 1). This trend may be even more pronounced, as the literature tends to be conservative. The next generation of cornea specialists, or at least the small sample that goes through our training programme, tends to fall into three categories: those who say guttae, those who correct others for saying guttata, and those who try their best not to mention the term for fear they're saying the wrong thing. Many of our faculty have now entered this last group.

When asked what is so bad about guttata, some insist that it is not the plural for gutta, the Latin word for drop. We're not sure that anyone ever said it was. More erudite dissenters recognise that not only is guttata not a plural, it is not even a noun-it's an adjective. The closest English counterpart to guttata is probably guttate, drop-like, or speckled, ${ }^{2}$ so it's incorrect to use guttata alone as a noun, or so the thinking goes. Some have chosen to use cornea guttata when referring to the condition, and guttae when referring to the excrescences themselves. ${ }^{1}$ 


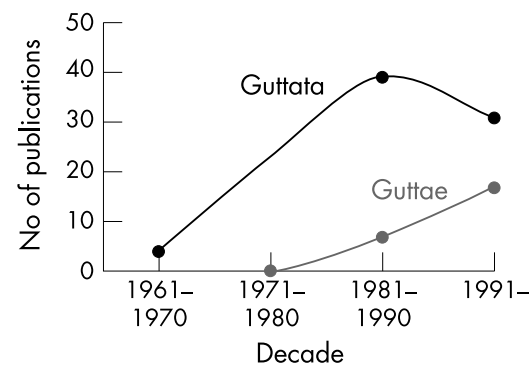

Figure 1 References to guttata and guttae over the past 40 years in Medline. Some articles use both terms. ${ }^{1}$

"Guttata were present" may well have grated the ears of an ancient Roman, since guttata is feminine singular, and Romans liked their subjects to agree with their verbs in number as much as the rest of us. However, it is not so clear that "Flavia's guttata is impressive" would be at all offensive, particularly since blonde Flavia herself was named after an adjective, as were Augustus and, some say, even Caesar himself. In fact, early Roman grammarians barely distinguished between adjectives and nouns, using them interchangeably any chance they could. ${ }^{3}$ The learned still do, at least when they refer to themselves as the learned. Those particularly offended by using an adjective substantively (as a noun) should be careful not to slip up with words like cornea. Both cornea and conjunctiva started out their ophthalmological careers as adjectives, modifying tunica (coat, feminine singular), which is why cornea and in turn, guttata are feminine singular in the first place.

What then should we call those excrescences on Descemet's membrane? Well, if you think they are drops, then by all means call them drops, although you probably don't need to invent yet another term from a dead language. Vogt called them "tropfige" (droplike) Prominenzen der Hornhautrückfläche before he coined cornea guttata (his quotes, not ours) ${ }^{4}$ If, like Dr Vogt, you want to convey that the cornea looks speckled with drop-like excrescences, then you could use the substantive adjective guttata as a singular noun, or the English guttate as an adjective. You could even use guttata as a plural noun-if criticised just say you were referring to the many droplike excrescentia (neuter plural), not a single speckled tunica cornea (feminine singular). A resident on our service recently wrote in a chart note guttatae (feminine plural). We certainly found no fault. In fact, it may be a reasonable compromise for those who have sworn never to use guttata. We find no reference to it yet in Medline.

T Lietman, J Lee, S Costanza FI Proctor Foundation and the Department of Ophthalmology, University of California, San Francisco, USA

Correspondence to: Thomas Lietman, MD, WHO Collaborating Center, Department of Ophthalmology, FI Proctor Foundation, University of California San Francisco, 95 Kirkham Street, Room 307, San Francisco, CA 94143-0944, USA tml@itsa.ucsf.edu

\section{References}

1 Borderie V, Sabolic V, Touzeau O, et al. Screening human donor corneas during organ culture for the presence of guttae. $\mathrm{Br}$ Ophthalmol 2001;85:272-6.

2 Glare PG. Oxford Latin dictionary. Oxford: Oxford University Press, 1983.
3 Humez A, Humez N D. Latin for people, Latina pro populo. Boston: Little, Brown, 1976.

4 Vogt A. Lehrbuch und Atlas Spaltlampenmikroskopie des Lebenden Auges. Berlin: Verlag von Julius Springer, 1930.

\section{Acanthamoeba keratitis}

We read with interest the report by Radford $e$ al on the incidence of acanthamoeba keratitis and the suggested relation with hardness of water. $^{1}$ However, we disagree with their findings and believe their study is flawed for two reasons.

Firstly, the incidence of acanthamoeba keratitis has been underestimated by approximately 33\% since their monthly questionnaire reporting system yielded an average return of only $67 \%$. A high non-response rate over $30 \%$ is considered unreliable for making inferences for the whole population. ${ }^{2}$ Furthermore, the authors estimated the "incidence" rate using the "complete" cases, which is a biased sample. Even then, if the non-response rates were below $30 \%$ in this study, the authors did not provide the precision of the "incident" rate and attempt to apply a statistical weighting approach to remove or reduce nonresponse bias.

Of 179 positive reports collected, only 106 $(59 \%)$ met their case definition criteria. This further reduced their number of cases but will have contributed to their diagnostic accuracy. A further five cases were excluded as non-UK residents but where did they acquire their infection-in the United Kingdom or overseas?

The incidence figures calculated for England and Wales for 1997-8 and 1998-9 of 0.21 and 0.18 per 10000 contact lens wearers (CLW) are thus an underestimate of the expected true infection rate. The expected true figure needs to be increased by a factor of $1.493(100 / 67)$ to account for the missed cases with the low reporting rate used of $67 \%$. The English figures then become $0.31(0.21 \times$ $1.493)$ and $0.27(0.18 \times 1.493)$ per 10000 CLW respectively, of whom the majority $(88 \%)$ wore soft hydrogel lenses.

These latter (corrected) figures for England and Wales are remarkably similar to the true figure estimated at the same time in a 17 month prospective cohort study in Hong $\mathrm{Kong}^{3}$ of 0.33 per 10000 "soft" hydrogel CLW Reporting "questionnaire" studies of infectious disease, albeit prospective and of new cases only, usually underestimate the true incidence figure by at least twofold and that used by the authors (BOSU) is no exception. Incidence figures for rare diseases are best estimated by performing a prospective cohort study, in which all cases occurring within a community of two million to three million people over a defined period (often a year or more) are examined and tested in severa referral hospitals according to defined criteria in advance.

Secondly, the authors suggest that there is a relation between water hardness and acquisition of acanthamoeba keratitis, on the basis of correlation of their questionnaire reports with water quality. They suggest a higher risk in areas of hard water but such findings are not supported by our results. In the west of Scotland, where there is very soft water (mean value for calcium carbonate $15.22 \mathrm{mg} / \mathrm{l}$ ), we recorded the highest incidence ever of acanthamoeba keratitis of 1.49 per 10000 "soft" hydrogel CLW in 1994-5 in a prospective cohort study. ${ }^{4}$ In Hong Kong, ${ }^{3}$ with an incidence of 0.33 per $10000 \mathrm{CLW}$, the water is also soft (mean value for calcium carbonate $40 \mathrm{mg} / \mathrm{l})$.
We believe that the suggested correlation by the authors of acanthamoeba keratitis with water hardness is spurious and demonstrates the danger of projecting "correlation" to "causation" within their study. The authors do not have definitive evidence to support their case because of sampling bias that results in part from evaluating associations between risk factors and a disease well after the risk exposure first occurs. During that time interval, cases of short duration or cases mild in severity or asymptomatic, and cases in which the presence of disease alters or entirely removes the exposure, are missed. ${ }^{5}$

Water "hardness" remains unproved as a risk factor for acanthamoeba keratitis being no more than an observational quirk. While we have had good molecular based evidence for the association of acanthamoeba keratitis with home tap water, ${ }^{6}$ recent work using $18 \mathrm{~S}$ rDNA typing and tracking has shown that there can be different subtypes of keratitis causing strains of Acanthamoeba spp (T4) between the tap water in the home and the cornea, making the epidemiology more involved. ${ }^{78}$

In conclusion, the incidence of acanthamoeba keratitis reported for England and Wales by the authors is an underestimate of the true figure by at least 33\%. The finding that the reporting of cases was "static" is of concern as it means that there is still need to reinforce ways of preventing this infection. ${ }^{9-11}$ While considerably less frequent since the introduction of multipurpose solutions 7 years ago, ${ }^{12}$ the infection remains a problem to be avoided by CL wearers as predicted by one of us 8 years ago. ${ }^{13}$ If good hygiene is practised, however, with monthly changing of storage cases, avoidance of tap water, and use only of sterile multipurpose solutions or overnight storage in hydrogen peroxide, then the risk of infection becomes negligible. Use of true daily disposable lens wear has also been virtually free of acanthamoeba infection.

Applied Vision Research Centre, City University, Northampton Square, London EC IV OHB, UK

T K Beattie, A Tomlinson Department of Vision Sciences, Glasgow Caledonian University, Cowcaddens Road, Glasgow G4 OBA, UK

D Fan, E Wong

Departments of Ophthalmology and Centre for Clinical Trials and Epidemiological Research (School of Public Health), Chinese University of Hong Kong, Prince of Wales Hospital, Shatin, NT, Hong Kong

Correspondence to: David Seal; 100756.3112@compuserve.com

\section{References}

1 Radford CF, Minassian DC, Dart JKG Acanthamoeba keratitis in England and Wales: incidence, outcome and risk factors. Br J Ophthalmol 2002;86:536-42.

2 Gail MH, Benichou J. Encyclopedia of epidemiologic methods. New York: John Wiley, 2000

3 Lam D, Houang E, Lyon D, et al. Incidence and risk factors for microbial keratitis in Hong Kong: comparison with Europe and North America. Eye 2002; 16:608-18.

4 Seal DV, Kirkness CM, Bennett HGB, et al. Population-based cohort study of microbial keratitis in Scotland: incidence and features. Contact Lens Ant Eye 1999:22:49-57.

5 Sackett DL. Bias in analytical research. J Chronic Disease 1979;32:51-63.

6 Ledee DR, Hay J, Byers TJ, et al. Acanthamoeba griffini: molecular characterisation of a new corneal pathogen. Invest Ophthalmol Vis Sci 1996;37:544-50. 
7 Schroeder JM, Booton GC, Hay J, et al. Use of subgenic 18s ribosomal DNA PCR and sequencing for genus and genotype identification of acanthamoebae from humans with keratitis and from sewage sludge. J Clin Microbiol 2001:39:1903-11.

8 Booton GC, Kelly DJ, Chu Y-W, et al. 18S Ribosomal DNA typing and tracking of Acanthamoeba sp from corneal scrape specimens, contact lenses, lens cases and home water supplies of acanthamoeba keratitis patients in Hong Kong. J Clin Microbiol 2002;40:1621-5

9 Fan D, Lam D, Houang E, et al. Health belief and health practice in contact lens wear $-a$ dichotomy? CLAO J 2002;28:36-9.

10 Houang $E$, Lam D, Fan D, et al. Microbial keratitis in Hong Kong-relationship to climate, environment and contact lens disinfection. Trans Roy Soc Trop Med Hyg 2001;95:361-7

11 Seal DV, Kirkness CM, Bennett HGB, et al. Acanthamoeba keratitis in Scotland: risk factors for contact lens wearers. Contact Lens Ant Eye 1999;22:58-68

12 Stevenson RWW, Seal DV. Has the introduction of multi-purpose solution contributed to a reduced incidence of Acanthamoeba keratitis in contact lens wearers? Contact Lens Ant Eye 1998;21:89-92

13 Seal DV. Acanthamoeba keratitis. A problem for contact lens users that is here to stay. BM 1994;308: $1116-17$.

\section{Surgery for glaucoma}

We would like to thank Drs Mermoud and Ravinet for their online comments on the editorial $^{1}$ and also for their comments on O'Brart's article (eletter posted on www. bjophthalmol.com 5 Aug 2002)

We are delighted that there is agreement that subconjunctival drainage is an important component of non-penetrating filtering surgery. Blebs, albeit diffuse, are clearly visible both in cases of deep sclerectomy, and in many cases of viscocanalostomy. However, although Ravinet and Mermoud and ourselves are certain that this is an important component for drainage in non-penetrating filtration surgery, it is important to clarify this point Although we are certain of the importance, there is still controversy over the relative importance of subconjunctival drainage versus other routes such as trans-scleral or via Schlemm's canal in the case of viscocanalostomy.

On the second point, although Mermoud and Ravinet use antimetabolites before cutting into the sclera, they do not apply antimetabolites including mitomycin into the deep scleral bed. Again, although they do not do this, we know that deep application has been used in other centres. Clearly, the risk of intraocular entry is higher in these situations, and that was the reason for making this com ment in the editorial, to warn people of the possible dangers of applying mitomycin after a deep scleral dissection.

Regarding the question of additional hypotony after macroperforation, clearly the team are very experienced in doing this surgery. However, from canvassing personal opinion from individuals who are doing this surgery, who are less experienced than them (like the majority of surgeons doing non-penetrating surgery), and also from reports in the literature including randomised prospective trials, macroperforation is associated with early hypotony. ${ }^{3}$ This may well be exacerbated if intraoperative antimetabolites, particularly mitomycin, have been used.

With regard to the comments on the paper by O'Brart et al, we have forwarded the contents of the letter on to the authors and they have replied separately to the comments.
In conclusion, we are pleased that the article and editorial have led to further healthy discussion. Mermoud and his colleagues are to be commended for the work they continue to do in non-penetrating filtration surgery. However, as we said in our editorial, current studies do reveal that none of the current operations for glaucoma are totally ideal yet, and further research, particularly on surgical methods and wound healing control, is needed so that optimal long term pressure control can be achieved for all our patients with a minimum of complications.

P T Khaw, A P Wells, K S Lim Moorfields Eye Hospital and the Institute of Ophthalmology, Bath Street, London ECIV 9EL, UK

Correspondence to: Peng T Khaw p.khaw@ucl.ac.uk

\section{References}

1 Khaw PT, Wells AP, Lim KS. Surgery in the 21 st century. $\mathrm{Br} J$ Ophthalmol 2002:86:710-11.

2 O'Brart DPS, Rowlands E, Islam N, et al. A randomised, prospective study comparing trabeculectomy augmented with antimetabolites with a viscocanalostomy technique for the management of open angle glaucoma uncontrolled by medical therapy. $\mathrm{Br}$ J Ophthalmol 2002;86:748-54.

3 Chiselita D. Non-penetrating deep sclerectomy versus trabeculectomy in primary open angle glaucoma surgery. Eye 2001;15:197-201.

4 El Sayyad F, Helal M, El Kholify H, et al. Nonpenetrating deep sclerectomy versus trabeculectomy in bilateral primary open angle glaucoma. Ophthalmology 2000;107:1671-4.

\section{A randomised controlled trial of written information}

Newsham's effort to inform parents of children with amblyopia about occlusion therapy is laudable but incomplete. ${ }^{1}$ Ethical considerations of informed consent require full disclosure of all aspects of the proposed treatment. The following points might be considered for inclusion

(1) Occlusion therapy has never been scientifically validated with a randomised, controlled study.

(2) The dose/response relation has never been defined. Flynn et al stated that "Success was not related to the duration of occlusion therapy, type of occlusion used ..."2 The variety of treatment protocols accentuates another dilemma "owing to our paucity of knowledge on the dose-effect relation-a situation one finds hard to imagine for any comparably established therapy outside ophthalmology. In other words we have no understanding of the dose-effect relation of occlusion in amblyopia therapy."

(3) The application of "greater levels of occlusion being prescribed for more severe amblyopia" ${ }^{\prime \prime}$ is compromised by the observation "that success was related to ... the depth of visual loss before treatment ..."

(4) The benefits of treatment are likely to deteriorate following cessation of patching. ${ }^{5}$

(5) Visual acuity improves as children become more mature, literate, and familiar with vision testing protocols. ${ }^{6}$ This is also true for amblyopic eyes. In amblyopic children between 3 and 7 years old without treatment visual acuity was shown to consistently improve in each older age group.

(6) Both the occluded and the amblyopic eyes improve at the same rate during treatment. ${ }^{8}$
(7) Success in amblyopia treatment is usually defined as improvement by a minimum of three lines. ${ }^{9}$ Many of the successfully treated patients, by that criterion, will still not have normal vision at the end of presumably successful treatment. One quarter of treated patients with initial acuity better than $20 / 100$ do not even achieve these limited goals. ${ }^{9}$ Therefore, the comments about achieving normal vision may raise expectations that will not be achieved.

(8) Occlusion therapy does have potential adverse effects beyond disruption of family and social life $^{10}$ and interference with education. ${ }^{11}$

(9) Despite decades of occlusion therapy the prevalence of amblyopia in the adult population is similar to that of the school age population. ${ }^{12}$ Moreover, "the prevalence of unilateral amblyopia was not found to be statistically different by age group." ${ }^{13}$ This suggests that long term benefits of conventional therapy are not demonstrated in demographic studies.

Patients and their families should be provided with comprehensive information concerning proposed treatments. Physicians are obliged to make this information accurate and inclusive.

P Lempert
Cornell University School of Veterinary Medicine

Ithaca, NY 14850, USA; eyechartplus@aol.com

\section{References}

1 Newsham D. A randomised controlled trial of written information: the effect on parental non-concordance with occlusion therapy. $\mathrm{Br} J$ Ophthalmol 2002;86:787-91.

2 Flynn JT, Schiffman J, Fever W, et al. The therapy of amblyopia: an analysis of the results of amblyopia therapy utilizing the pooled data of published studies. Trans Am Ophthalmol Soc 1998;96:431-50; discussion 450-3.

3 Simonsz HJ, Polling JR, Voorn R, et al. Electronic monitoring of treatment compliance in patching for amblyopia. Strabismus 1999; 7: $113-23$

4 Beardsell R, Clarke S, Hill M. Outcome of occlusion treatment for amblyopia. J Pediatr Ophthalmol Strabismus 1999:36:19-24.

5 Von Noorden GK, Attiah F Alternating penalization in the prevention of amblyopia recurrence. Am J Ophthalmol 1986;102:473-5.

6 Robinson BE, Oladeji MM, Bobier WR. Visual acuity assessment in preschool children in Oxford County. ARVO 2000 Abstract No 4955.

7 The Pediatric Eye Disease Investigator Group. The clinical profile of moderate amblyopia in children younger than 7 years. Arch Ophthalmol 2002;1 20:281-7.

8 Dorey SE, Adams GG, Lee JP, et al. Intensive occlusion therapy for amblyopia. $\mathrm{Br} J$ Ophthalmol 2001:85:310-13.

9 The Pediatric Eye Disease Investigator Group. A randomized trial of atropine vs patching for treatment of moderate amblyopia in children. Arch Ophthalmol 2002:120:268-78

10 Snowdon SL, Stewart-Brown SL. Amblyopia and disability: a qualitative study. Oxford: Health Services Research Unit University of Oxford.

11 Yang LL, Lambert SR. Reappraisal of occlusion therapy for severe structural abnormalities of the optic disc and macula. $J$ Pediatr Ophthalmol Strabismus 1995:32:37-41.

12 Buch $\mathbf{H}$, Vinding T, La Cour $M$, et al. The prevalence and causes of bilateral and unilateral blindness in an elderly urban Danish population. The Copenhagen City Eye Study Acta Ophthalmol Scand 2001;79:441-9.

13 Brown SA, Weih LM, Fu CL, et al. Prevalence of amblyopia and associated refractive errors 
in an adult population in Victoria, Australia. Ophthalmic Epidemiol 2000;7:249-58.

\section{Ocular and financial health}

We read with interest the article by Khandekar et al detailing the results of the 1996-7 Omani Eye Study. ${ }^{1}$ They found a prevalence of blindness of $16.8 \%$ in those $60+$ years of age, and comment that the popula tion of this age group in Oman is predicted to double by the year 2020. This has serious implications for planning the provision of health care and specifically for eye care services.

This observation is true for most countries the global population for the over 65 age group is projected to increase from approximately 400 million to 800 million people by the year 2020, contrasting with the under 5 years of age population, which is estimated to see a $6 \%$ growth in the same period. ${ }^{2}$

"Vision 2020-the right to sight" was launched by the WHO and IAPB in 1999, aim ing for the elimination of avoidable blindness by the year 2020. In 1995 the estimate of global blindness $(<3 / 60$ better eye) was 44 million, and this is projected to rise to $76 \mathrm{mil}$ lion by 2020 if there is no change in curren trends. ${ }^{3}$ Vision 2020 prioritises five disease for global attention-cataract, refractive errors, trachoma, onchocerciasis, and vitamin $A$ deficiency. Action against diabetic retinopathy and glaucoma is also deemed important in countries where ocular infections have been controlled. Vision 2020 contends that the current increase in blindness, estimated at 1-2 million people per year, can be reversed if human and financial resources are targeted at these priority diseases in the countries with the highest prevalence and number of blind people. It is estimated that the result of a successful programme, achievable at a cost of $\$ 2$ billion, will be 429 million blind person years avoided over the next 20 years, and a tota saving in excess of $\$ 100$ billion, by avoidance of lost productivity. ${ }^{3}$ This would make the effective implementation Vision 2020 not only ethically important but also a cost effective strategy for poverty alleviation.

J C Buchan, C Gilbert London School of Hygiene and Tropical Medicine, Keppel Street, London WC1E 7HT, UK

Correspondence to: John Buchan john.buchan@|shtm.ac.uk

\section{References}

1 Khandekar R, Mohammed AV, Negrel AD, et al. The prevalence and causes of blindness in the Sultanate of Oman: the Oman Eye Study (OES). Br J Ophthalmol 2002;86:957-62.

2 www.census.gov/ipc/prod/wp98/wp98.pdf

3 Frick KD, Foster $A$. The magnitude and cost of global blindness: an increasing problem that can be alleviated. Am J Ophthalmol (in press).

\section{BOOK REVIEWS}

\section{Ocular Pathology, 5th ed.}

Myron Yanoff, Ben S Fine. Pp 700; 180. St Louis: Mosby, 2002. ISBN 0323014038.

The fifth edition of this well established ocular pathology text is excellent. The presentation, the photographs, the histopathology, and micrograph sections provide the reader with an array of outstanding examples of ocular pathology. The text is easy to read, agreeably not always in depth, but gives enough information or direction in references for further reading. This is being hypercritical of an enjoyable text and there is no more to say except that every unit and library should update their edition.

A Dick

\section{The History of Strabismology: Hirschberg History of Ophthalmology: The Monographs.}

von Noorden GK, ed. US\$145. Belgium: Wayenborgh, 2002.

For those who specialise in the treatment of ocular motility disorders, it seems at times as though time has stood still. Compared with the technical and surgical innovations that have characterised the modern history of the treatment of cornea and retinal diseases, strabismologists have continued to use techniques and instruments devised in the mid19 th century. However, after reading von Noorden's The History of Strabismology, it becomes clear that the history of our specialty has been characterised by physicians and scientists possessing remarkable creativity and intellect striving to understand how the eyes move and the brain sees.

The History of Strabismology is the ninth volume of The History of Ophthalmology, a planned 21 volume series of monographs intending to comprehensively review the history of ophthalmology from ancient times to the current day. The author has chosen to review the history of strabismology not with a traditional "art through the ages" chronological approach, but rather from a geocentric approach. By enlisting prominent strabismologists from around the world as contributing authors, von Noorden allows the reader to discover how the discipline and practice of strabismology developed and evolved not just in Europe and the United States, but in countries and regions such as Mexico, Japan, South America, and Australia. In thoroughly researched and referenced chapters, the authors describe, time and again, how an ophthalmologist visiting Europe learns a technique, returns to his or her country, refines the technique and applies it to the patient population unique to his or her country. We learn of scoundrels and rogues who foist themselves on the public as miracle workers, only to be publicly exposed and discredited by ethical ophthalmologists of the day (lessons we could stand to relearn now again in the 21 st century). We learn that aesthetic ideals are relative to time and place such as the fact that in pre-Columbian times a slight degree of esotropia was found to be attractive and convergence was stimulated in infants by attaching a ball of beeswax to the child's hair to be left dangling between the eyes (vision therapy at its birth).

An often neglected but historically important discipline within the field of strabismus is the practice of orthoptics. In a carefully researched and beautifully illustrated chapter, section author Roper-Hall outlines the origins of the specialty and introduces us to the pioneering women and men who selflessly served, taught, and discovered in the clinics of the more famous titans of strabismology. Throughout the book, von Noorden takes pains to illuminate the lives and contributions of both major and minor players in the history of strabismus. The reader cannot help but see how the advancement of science in a discipline is dependent upon the close collaboration that takes place between mentor and student, doctor and patient, and clinician and scientist.

As with all the monographs in this series, the volume contains extensive illustrations, photographs and reproductions. Portraits and photographs of innovators in the field of strabismology flesh out the names we associate with instruments and techniques. Each section author provides numerous references of seminal papers on strabismus published from the corners of the globe. It is refreshing to see a book on history recognise the contributions from those outside the traditional medical centres of Europe/United Kingdom and the United States.

This book will be a valuable reference for all those who specialise in the area of strabismus and those interested in the history of ophthalmology. The illustrations and historical references will greatly enhance the quality of lectures on the topic of strabismus. Knowledge of the origins of critical thought and technical innovation concerning the aetiology and treatment of strabismus will stimulate further interest in today's students of ophthalmology. Finally, the knowledge that the pioneers of ophthalmology-von Graefe, Muller, Donders, and Helmholtz-placed the study and treatment of strabismus at an equal level of importance as the treatment of diseases of the lens, cornea, and retina serves notice to contemporary vision scientists and ophthalmologists not to neglect this most challenging discipline of ophthalmologystrabismus.

D R Fredrick San Francisco

\section{NOTICES}

\section{Role of optometry in Vision $\mathbf{2 0 0 0}$}

The latest issue of Community Eye Health (No 43 ) discusses the mobilisation of optometry to deal with uncorrected refractive error, which is now a major cause of functional blindness. For further information please contact: Journal of Community Eye Health, International Centre for Eye Health, Institute of Ophthalmology, 1 1-43 Bath Street, London EC IV 9EL UK (tel: +44 (0)20 7608 6910; fax: +44 (0)20 7250 3207; email: eyeresource@ucl.ac.uk; web site: www.jceh.co.uk). Annual subscription (4 issues) UK£25/US\$40. Free to workers in developing countries.

\section{International Centre for Eye Health}

The International Centre for Eye Health has published a new edition of the Standard List of Medicines, Equipment, Instruments and Optical Supplies (2001) for eye care services in developing countries. It is compiled by the Task Force of the International Agency for the Prevention of Blindness. Further details: Sue Stevens, International Centre for Eye Health, 11-43 Bath Street, London ECIV 9EL UK (tel: +44 (0)20 7608 6910; email: eyeresource@ucl.ac.uk).

\section{Second Sight}

Second Sight, a UK based charity whose aims are to eliminate the backlog of cataract blind in India by the year 2020 and to establish 
strong links between Indian and British ophthalmologists, is regularly sending volunteer surgeons to India. Details can be found at the charity web site (www.secondsight.org.uk) or by contacting Dr Lucy Mathen (lucymathen@ yahoo.com).

\section{SPecific Eye ConditionS (SPECS)}

SPecific Eye Conditions (SPECS) is a not for profit organisation which acts as an umbrella organisation for support groups of any conditions or syndrome with an integral eye disorder. SPECS represents over fifty different organisations related to eye disorders ranging from conditions that are relatively common to very rare syndromes. We also include groups who offer support of a more general nature to visually impaired and blind people. Support groups meet regularly in the Boardroom at Moorfields Eye Hospital to offer support to each other, share experiences and explore new ways of working together. The web site www.eyeconditions.org.uk acts as a portal giving direct access to support groups own sites. The SPECS web page is a valuable resource for professionals and may also be of interest to people with a visual impairment or who are blind. For further details about SPECS contact: Kay Parkinson, SPECS Development Officer (tel: +44 (0)1803 524238; email: k@eyeconditions.org.uk;web site: www.eyeconditions.org.uk).

\section{The British Retinitis Pigmentosa Society}

The British Retinitis Pigmentosa Society (BRPS) was formed in 1975 to bring together people with retinitis pigmentosa and their families. The principle aims of BRPS are to raise funds to support the programme of medical research into an eventual cure for this hereditary disease, and through the BRPS welfare service, help members and their families copy with the everyday concerns caused by retinitis pigmentosa. Part of the welfare service is the telephone help line $(+44$ (0) 1280860363 ), which is a useful resource for any queries or worries relating to the problems retinitis pigmentosa can bring. This service is especially valuable for those recently diagnosed with retinitis pigmentosa, and all calls are taken in the strictest confidence. Many people with retinitis pigmentosa have found the Society helpful, providing encouragement, and support through the Help line, the welfare network and the BRPS branches throughout the UK. (tel: +44 (0)1280 821 334; email: lynda@brps.demon.co.uk; web site: www.brps.demon.co.uk)

\section{Surgical Eye Expeditions International}

Volunteer ophthalmologists in active surgical practice are needed to participate in short term, sight restoring eye surgery clinics around the world. Contact: Harry S Brown, Surgical Eye Expeditions International, 27 East De La Guerra, C-2, Santa Barbara, CA 93101-9858, USA (tel: +805 9633303 fax: $\quad+805 \quad 965$ 3564; email: hsbrown.md@cox.net or seeintl@seeintl.org; web site: www. seeintl.org).

\section{6th Annual Meeting of German Ophthalmic Surgeons}

The 16th Annual Meeting of German Ophthalmic Surgeons will be held 8-11 May 2003 in Nürnberg, Germany, Messezentrum. Organised by the Professional Association of German Ophthalmologists Ophthalmic Surgery Group the conference will cover cataract surgery, refractive surgery, glaucoma surgery, vitreoretinal surgery, corneal surgery, eye surgery in developing countries, and orbita, lacrimal and lid surgery. Further details: MCN Medisinische Congress organisation Nürnberg AG, Zerzabelshofstr 29, 90478 Nürnberg, Germany (tel:+49 911 3931621; fax: +49 911 3931620; email: doc@mcnag.info; web site: www.doc-nuernberg.de)

\section{3rd British Oculoplastic Surgery Society Meeting}

The 3rd British Oculoplastic Surgery Society Meeting will be held 18-19 May 2003 in Birmingham, UK. For further details please contact the Secretary of the British Oculoplastic Surgery Society Jane Olver (tel: +44 (0)121 424 5464; fax: +44 (0)121 4244464 email: MartiDi@heartsol.wmids.nhs.uk; web site: www.bopss.org)

\section{3th Meeting of the EASD Eye Complication Study Group}

The 13th Meeting of the EASD Eye Complication Study Group will be held on the 23-25 May 2003, in Prague, Czech Republic. The scientific programme includes keynote lectures from Professor John H Fuller (UK) on The epidemiology of diabetic retinopathy; $\mathrm{Dr} P$ Martin van Hagen (The Netherlands) on Growth factors and diabetic retinopathy; Professor Terezie Pelikanova (Czech Republic) on Pathophysiology of diabetic microvascular complications; Dr Tomas Sosna (Czech Republic) on Risk and protective factors of diabetic retinopathy.
Further details: Ortopedicke Centrum, s.r.o., Strekovské nabrezi 51, 40003 Usti nad Labem, Czech Republic (tel: +420 47521 6588; fax: +420 4753340 77; email: ortcentrum-ul@volnv.cz; web site: www.ortopedicke-centrum.cz).

\section{IOIS-VIIth International Symposium on Ocular Inflammation}

The IOIS-VIIth International Symposium on Ocular Inflammation will be held 25-30 May 2003, in Padova, Italy.

Programme and Organising Committee: Prof. Antonio Secchi, Chairman of IOIS and Convenor of Congress (email: ag.secchi@unipd.it). Further details: Congress Secretariat, Meet and Work, Mario Sbalchiero (tel: +39 049860 1818: fax: +39049 860 2389; email: info@iois-2003.com; web site: www.meetandwork.com).

\section{Retinal Detachment Course}

The XXXII Retinal Detachment Course with International Faculty and Case Presentations will be held 5-6 June 2003, in Beijing, China. The Congress language is English with simultaneous translation in Chinese. Further details: Scientific programme: Prof Ingrid Kreissig, University of Tuebingen, Schleichstr. 12, Breuningerbau, 72076 Tuebingen, Germany (tel: $\quad+49$ 7071 295209; email: ingrid.kreissig@med.uni-tuebingen.de).

Local organisation: Ningli Wang, Liang Xu, Wu Liu. Congress office: Wu Liu, Beijing Tong Ren Eye Center, Beijing 100730 China (email: wuliubj@yahoo.com).

\section{Detachment Course with international faculty on: Retinal and Vitreous Surgery with Case Presentations preceding the Annual Meeting of Iranian Society of Ophthalmology}

The detachment course with international faculty on: Retinal and Vitreous Surgery with Case Presentations preceding Annual Meeting of Iranian Society of Ophthalmology will be held on 29-30 November 2003 and 1-4 December 2003 respectively, at the Razi Conference Center, Hemmat Hyw, Tehran, Iran. Further details: Scientific programme: Prof Ingrid Kreissig, University of Tuebingen, Schleichstr. 12, Breuningerbau, 72076 Tuebingen, Germany (tel: +49 7071 295209; email:ingrid.kreissig@med.uni-tuebingen.de). Local organisation: Dr Arman Masheyekhi, Dr Siamak Moradian, Dept of Ophthalmology, Labbanfinejad Medical Center, Pasdaran Ave, Boostan 9, Tehran, 16666, Iran (fax: +98 21254 9039; email: labbafi@hotmail.com). 